\title{
In Vitro Susceptibility of Fungi to Killing by Neutrophil Granulocytes Discriminates between Primary Pathogenicity and Opportunism
}

\author{
Andreas Schaffner, * Charles E. Davis,‡ Thomas Schaffner,§ Michele Markert,\| \\ Herndon Douglas, $\neq$ and Abraham I. Braude $\neq t$ \\ *Department of Medicine, University of Zürich, Zürich; §Department of Pathology, University of Bern, Bern; and $\|$ Laboratoire Centrale \\ de Chimie Clinique, University Hospital Lausanne, Lausanne, Switzerland; $\ddagger$ Departments of Medicine and Pathology, University of \\ California at San Diego, San Diego, California 92103
}

\begin{abstract}
Pathogenic fungi, according to their propensity to cause infection of apparently normal individuals, can be grouped into either primary pathogens (e.g., Coccidioides, Histoplasma, Paracoccidioides, Blastomyces, and Sporothrix) or opportunists (e.g., Candida, Mucoraceae, Aspergillus spp., Petriellidium, and Trichosporon). There is, however, no unifying concept explaining the difference between the virulence of the two fungal categories. Previously we have speculated that neutrophils are the common denominator of the high natural resistance to opportunistic fungi. Accordingly, we then compared the susceptibility to killing by neutrophil granulocytes of Histoplasma, Blastomyces, Paracoccidioides, and Sporothrix with that of 14 opportunistic fungi. We found the four virulent dimorphic yeasts, in contrast to opportunistic fungi, to be resistant to killing by neutrophils. Virulent dimorphic yeasts were ingested by neutrophils, and triggered a respiratory bursteomparably to opportunists but were less susceptible to hydrogen peroxide, suggesting that differences in the susceptibility to microbicidal products of leukocytes may explain the difference in virulence.
\end{abstract}

\section{Introduction}

Normal people inhale thousands of fungal spores every day $(1,2)$ and harbor many fungi on their mucosal surfaces $(3)$, but seldom develop invasive mycotic infections. Thus, most potentially pathogenic fungi are opportunists and cause serious infection only in individuals with defective host defense systems (4-7). In contrast, a few fungi can cause serious and progressive infection in apparently normal people (7-9) and occasionally are even responsible for large outbreaks of disease such as the recent epidemic of histoplasmosis in Indianapolis, IN (8). These virulent fungi are all dimorphic; that is, they grow as molds in their saprophytic phase, but dispense with hyphal growth in the host (7) and reproduce as single-celled yeasts (Histoplasma, Blastomyces, Paracoccidioides, and Sporothrix) or as spherules (Coccidioides) in tissues. There is evidence that dimorphism is responsible for the pathogenicity of these virulent fungi because none of the monomorphic molds, which depend on hyphal

† Dr. Braude died on 6 December 1984

Address reprint requests to Dr. Schaffner, Room CH 13, Universitätsspital, CH-8091 Zürich, Switzerland.

Received for publication 1 October 1985 and in revised form 25 April 1986.

J. Clin. Invest.

(C) The American Society for Clinical Investigation, Inc.

0021-9738/86/08/0511/14 \$1.00

Volume 78, August 1986, 511-524 growth in the host (e.g., Aspergillus spp., Mucorales, and Petriellidium), affect normal people. Even the fungi that display reverse dimorphism (e.g., Candida albicans and Trichosporon spp.), which grow as yeasts on many culture media but predominantly as hyphae in tissues, are incapable of causing systemic infections in normal individuals (7). These observations suggest that there are defense mechanisms that protect normal individuals from hyphal fungi, which are, however, ineffective against the specialized tissue phase of the virulent dimorphic fungi.

Experimental evidence suggests that neutrophil granulocytes $(\mathrm{PMN})^{1}$ provide this reliable protection against hyphae. We have recently shown that PMN prevent experimental aspergillosis by killing the mycelia of Aspergillus fumigatus (10), and Diamond et al. $(11,12)$ have shown that PMN damage the hyphae of Rhizopus and C. albicans. Furthermore, opportunistic yeasts are efficiently killed by PMN in vitro $(13,14)$. In the present study, we tested the hypothesis that the susceptibility of fungi to killing by PMN discriminates between the broad range of opportunistic fungi and the virulent tissue phase of dimorphic fungi. Our results show that yeast cells from virulent dimorphic fungi, in contrast to opportunistic yeasts or hyphae, survive in vitro phagocytosis by PMN. These findings support the view that PMN are the common denominator of the high natural resistance of normal people to opportunistic fungi and suggest that the primary pathogenicity of virulent dimorphic fungi depends on their resistance to killing by PMN.

\section{Methods}

Organisms. The fungi studied are listed in Table I. Spores from Aspergillus spp., Mucorales, and $P$. boydii were obtained by scraping 10-18-d-old culture slants of Sabouraud dextrose agar and purified from mycelial components and clumps as described previously (10). If not stated otherwise yeasts were cultured as follows: Opportunistic yeasts were obtained by sedimentation of overnight growth $\left(37^{\circ} \mathrm{C}\right)$ in brain-heart infusion broth (BHI). Yeast cells from $B$. dermatitidis were grown for 3-8 d in $\mathrm{BHI}$ at $37^{\circ} \mathrm{C}$; the yeast phase of $S$. schenkii was grown for $48 \mathrm{~h}$ in a thin layer of trypticase soy broth (TSB) at $37^{\circ} \mathrm{C}$ in an atmosphere of $5 \% \mathrm{CO}_{2}$ in disposable petri dishes. Histoplasma capsulatum was grown in BHI supplemented with $0.1 \%$ cysteine for $5-8 \mathrm{~d}$ at $37^{\circ} \mathrm{C}$. Clumps of yeast cells were disrupted by gentle homogenization with a Teflon pestle and filtration through a 12-ml syringe packed with cotton gauze. Concentrations of washed yeast and spores were adjusted by hemocytometer counts and verified by determining the number of colony-forming units (CFU) in pour plates (10).

1. Abbreviations used in this paper: AIDS, acquired immunodeficiency syndrome; BHI, brain-heart infusion; CFU, colony-forming unit(s); GBSS, Gey's balanced salt solution; HRP, horseradish peroxidase; HS, human serum; MEM, minimal essential medium; PMN, polymorphonuclear granulocyte(s); TSB, trypticase soy broth. 
Table I. Fungi Studied

\begin{tabular}{|c|c|c|c|}
\hline ID & Organism & Isolated from & Source \\
\hline $\mathrm{AF}$ & Aspergillus fumigatus & Invasive disease & UZ \\
\hline AFl & Aspergillus flavus & Invasive disease & UCSD \\
\hline AN & Aspergillus niger & Sputum & UCSD \\
\hline $\mathbf{M}$ & Mucor spp. & Invasive disease & UCSD \\
\hline A & Absidia corymbifera & Invasive disease & UZ \\
\hline $\mathbf{R}$ & Rhizopus oryzae & Invasive disease & ATCC 11886 \\
\hline $\mathbf{P}$ & Petriellidium boydii & Invasive disease & UCSD \\
\hline CA-1 & Candida albicans & Fungemia & UCSD \\
\hline CA-2 & Candida albicans & Fungemia & HRB \\
\hline CA-3 & Candida albicans & Fungemia & HRB \\
\hline $\mathrm{CA}-4$ & Candida albicans & Fungemia & HRB \\
\hline CA-5 & Candida albicans & Fungemia & HRB \\
\hline CA-6 & Candida albicans & Fungemia & HRB \\
\hline CK & Candida krusei & Fungemia & HRB \\
\hline CT & Candida tropicalis & Fungemia & HRB \\
\hline $\mathrm{CP}$ & Candida parapsilosis & Fungemia & HRB \\
\hline CPT & Candida pseudotropicalis & Fungemia & HRB \\
\hline TG & Torulopsis glabrata & Fungemia & HRB \\
\hline TC & Trichosporon capitatum & Fungemia & $\mathrm{UZ}$ \\
\hline H-1 & Histoplasma capsulatum & Invasive disease & ATCC 26028 \\
\hline $\mathrm{H}-2$ & Histoplasma capsulatum & Invasive disease & WUSL \\
\hline $\mathrm{H}-3$ & Histoplasma capsulatum & Invasive disease & WUSL \\
\hline $\mathrm{H}-4$ & Histoplasma capsulatum & Invasive disease & WUSL \\
\hline H-5 & Histoplasma capsulatum & Invasive disease & WUSL \\
\hline H-6 & Histoplasma capsulatum & Laboratory strain & WUSL \\
\hline S-1 & Sporothrix schenkii & Disseminated disease & UCSD \\
\hline S-2 & Sporothrix schenkii & Disseminated disease & UM \\
\hline S-3 & Sporothrix schenkii & Localized disease & UM \\
\hline$S-4$ & Sporothrix schenkii & Disseminated disease & UM \\
\hline S-5 & Sporothrix schenkii & Disseminated disease & UM \\
\hline S-6 & Sporothrix schenkii & Localized disease & UM \\
\hline B-1 & Blastomyces dermatitidis & Not known & ATCC 26198 \\
\hline B-2 & Blastomyces dermatitidis & Human disease & ATCC 26199 \\
\hline PB-1 & $\begin{array}{l}\text { Paracoccidioides } \\
\text { brasiliensis }\end{array}$ & Disseminated disease & USM \\
\hline PB-2 & $\begin{array}{c}\text { Paracoccidioides } \\
\text { brasiliensis }\end{array}$ & Disseminated disease & USM \\
\hline
\end{tabular}

Abbreviations: ID, identification label; UZ, University of Zürich; UCSD, University of California at San Diego Medical Center, ATCC, American Type Culture Collection (Rockville, MD); HRB, Hoffmann-La Roche Strain Collection (Basel, Switzerland); WUSL, Washington University (St. Louis, MO); UM, University of Mexico City; USM, University Hospital (Santa Maria, Brazil).

Media and reagents. Sabouraud dextrose agar, TSB, and BHI broth were obtained from Difco Laboratories, Detroit, MI. Minimal essential medium (MEM), Medium 199, Gey's balanced salt solution (GBSS), fetal bovine serum, and penicillin-streptomycin were obtained from Gibco Laboratories, Grand Island, NY. Human serum (HS) was separated from the blood of normal volunteers after coagulation at room temperature for $1 \mathrm{~h}$ and storage overnight at $4^{\circ} \mathrm{C}$ by centrifugation at $140 \mathrm{~g}$ and recentrifugation at $1,500 \mathrm{~g}$ for $10 \mathrm{~min}$. Sodium azide, superoxide dismutase, catalase, Isopaque-Ficoll, preservative-free heparin, bovine serum albumin, luminol, lucigenin, and scopoletin were obtained from Sigma Chemical Co., Saint Louis, MO; human serum albumin was from the Swiss Red Cross (Bern, Switzerland), and dextran 3\% (average mol wt 250,000 ) was obtained from Pharmacia, Inc., Piscataway, NJ. Lyophilized mannan was prepared from a wild strain of $C$. albicans according to the hot formamide method of Kerkering et al. (15).

Leukocytes. Human peripheral venous blood was taken from normal volunteers, and anticoagulated with $10 \mathrm{U} / \mathrm{ml}$ heparin, and the leukocytes separated by dextran sedimentation and further fractionated by Ficoll gradient (16). This gave mononuclear and PMN preparations with a purity of $>97 \%$ each, as determined by Giemsa morphology. In some experiments the mononuclear cell fraction was further enriched with, or depleted of, monocytes by glass adherence. For this purpose $5 \times 10^{7}$ cells were suspended in GBSS supplemented with 5\% HS and incubated for $20 \mathrm{~min}$ in a glass petri dish before removing nonadherent cells by three washes with prewarmed GBSS. Adherent cells were then removed by vigorous pipetting with ice-cold GBSS for $10 \mathrm{~min}$. This gave a glass adherence-depleted cell fraction with $<10 \%$ monocytes (Giemsa morphology) and a monocyte-enriched cell fraction with $>65 \%$ monocytes. Viability of leukocytes was always $>96 \%$ as judged by trypan blue exclusion. Concentrations of washed cells suspended in MEM supplemented with $10 \%$ HS were adjusted by hemocytometer counts.

Microwell assay for killing by leukocytes. Killing was assessed by our method that solves the problem of counting viable hyphae (10). This test measures the capacity of leukocytes to sterilize microwells inoculated with a small number of yeast or hyphae obtained from a small number of spores or yeast. In experiments with hyphal forms, leukocytes are not added until $100 \%$ of the yeasts or spores have transformed into hyphae. After predetermined time intervals, the leukocytes are lysed with distilled water, and fresh medium is added to permit outgrowth of surviving hyphae. Results are expressed as the number of wells sterilized over the total number of wells inoculated. The assay was begun by pipetting 100 $\mu \mathrm{l}$ of a suspension of yeast or spores suspended in MEM with $10 \%$ fetal bovine serum (serial dilutions of 20-200 CFU/ml) into flat-bottomed $350-\mu$ l cluster wells (96-well tissue culture clusters, $0.32 \mathrm{~cm}^{2}$, Costar Data Packaging, Cambridge, MA). After 4-72 h of incubation at $25^{\circ} \mathrm{C}$ or $37^{\circ} \mathrm{C}$, depending on the fungus, complete transformation of spores or yeast into hyphae was verified by phase-contrast microscopy. To measure killing of yeast cells, identical suspensions were added to wells immediately prior to the following steps. Care was taken not to expose dimorphic yeast to temperatures below $37^{\circ} \mathrm{C}$ for more than $30 \mathrm{~min}$. Plates were then centrifuged at $800 \mathrm{~g}$ to sediment the fungi, the medium was replaced by $1-2 \times 10^{5}$ leukocytes suspended in $100 \mu \mathrm{l}$ with $10 \%$ HS or MEM with HS alone, and the leukocytes were sedimented by $100 \mathrm{~g}$ for $60 \mathrm{~s}$. After these steps, both hyphae and leukocytes covered $10-30 \%$ of the surface. Migration of leukocytes toward fungal cells and attack of fungi was observed under the phase-contrast microscope. The interaction between leukocytes and fungi was stopped at indicated times by adding $100 \mu \mathrm{l}$ of distilled water for selective lysis of leukocytes and then $100 \mu \mathrm{l}$ of double-strength BHI (supplemented with $200 \mathrm{U} / \mathrm{ml}$ penicillin and $200 \mu \mathrm{g} / \mathrm{ml}$ streptomycin) to promote fungal growth. For $H$. capsulatum, BHI was supplemented with cysteine. Wells were inspected for fungal colonies for either $4 \mathrm{~d}$ (opportunistic fungi) or $21 \mathrm{~d}$ (Histoplasma, Paracoccidioides, Blastomyces, and Sporothrix). To prevent cross-contamination of wells, one drop of $5 \%$ aqueous methylene blue was placed in wells as soon as growth was observed, which was uniformly within $48 \mathrm{~h}$ after lysis of leukocytes for opportunistic fungi and within $10 \mathrm{~d}$ for dimorphic yeasts. In preliminary experiments with Aspergillus and Rhizopus, 1-3 $\times 10^{5}$ leukocytes sterilized a maximum number of wells.

Assay for killing of yeast by PMN in suspension. $5 \mathrm{ml}$ of purified PMN $\left(1 \times 10^{6} / \mathrm{ml}\right)$ were mixed with $5 \mathrm{ml}$ of yeast cells $\left(1 \times 10^{5} / \mathrm{ml}\right)$, both suspended in prewarmed Medium 199 supplemented with $10 \%$ HS in triplicate 10-ml polypropylene tubes (Falcon Plastics, Oxnard, CA) and tumbled on a rotatory shaker at $37^{\circ} \mathrm{C}$. At indicated times, $0.5 \mathrm{ml}$ of the suspension was removed and placed into $4.5 \mathrm{ml}$ of sterile water to lyse the phagocytes and vortexed several times. Viability of fungi was then determined by culturing serial 1:10 dilutions of the lysate in TSB on blood agar plates ( $10 \%$ rabbit blood, BHI, $2 \%$ agar, supplemented with $0.1 \%$ cysteine for Histoplasma). The plating efficiency (number of colony-forming units per milliliter over the number of counted fungi per milliliter $\times 100$ ) was above $90 \%$ in all experiments for all fungi except for $B$. dermatitidis and $P$. brasiliensis, which were therefore not studied by this technique. For determination of changes in stainability of yeast cells after phagocytosis (14), 10 drops of the suspensions were centrifuged at the indicated time points on glass slides with the help of a cytospin (Shandon \& Southern Ltd., Cheshire, England) set at 500 $\mathrm{rpm}$. Slides were then air-dried and stained simultaneously by the MayGiemsa-Grünwald method in an automated slide stainer (Shandon Elliot Instruments Ltd., Surrey, England). For studies of ultrastructural alterations of fungi, 50\% glutaraldehyde was added to a final concentration of $2.5 \%$ at indicated times to tubes with PMN and fungi. After fixation for $15 \mathrm{~min}$ at $37^{\circ} \mathrm{C}$, the cells were pelleted by centrifugation for $10 \mathrm{~min}$ 
at $400 \mathrm{~g}$ and the supernatant was replaced by $2.5 \%$ glutaraldehyde in $0.1 \mathrm{M}$ cacodylate, $\mathrm{pH}$ 7.4. Pellets were postfixed in osmium tetroxide, dehydrated in ethanol and propylene oxide, and embedded in Spurr's epoxy resin. Thin sections contrasted with Sato's permanganate/lead stain were photographed on a EM 10 B (Carl Zeiss, Oberkochen, Federal Republic of Germany). All cells of at least two separate pellets present in the mesh spaces of an entire single section were evaluated for each condition reported.

Susceptibility of fungi to oxidants. For determination of the susceptibility of fungi to oxidants, the microwell assay for killing by leukocytes was adapted for cell-free killing systems. Microwells were inoculated with 20-30 CFU of spores or yeast, incubated for transformation into mycelia as described above, and centrifuged, and the supernatant was replaced by $100 \mu$ l of serial 1:3 dilutions of the oxidants in buffer as indicated. After incubation for $45 \mathrm{~min}$ at $37^{\circ} \mathrm{C}$, the reaction was quenched by adding $200 \mathrm{U}$ of catalase to wells with $\mathrm{H}_{2} \mathrm{O}_{2}$ and $10 \mu \mathrm{l}$ of $0.1 \mathrm{M}$ sodium thiosulfate (17) to wells with $\mathrm{ClO}^{-}$. After centrifugation of wells at $800 \mathrm{~g}$ for $15 \mathrm{~min}$ the supernatant was replaced by $100 \mu \mathrm{l}$ of the appropriate culture medium to permit fungal outgrowth. The fungicidal activity of the oxidants is given as the $50 \%$ effective dose $\left(\mathrm{ED}_{50}\right)$, computing the results from six wells per dilution. Alternatively, killing of yeast cells by cell-free oxidative systems was followed by determining the loss of CFU over time by quantitative culture of serial dilutions in BHI supplemented with catalase. Catalase activity of fungal cell homogenates was measured by continuously recording the reduction of absorbance by $\mathrm{H}_{2} \mathrm{O}_{2}$ at $240 \mathrm{~nm}$ as described previously (18). Protein concentrations of homogenates were measured by the method of Lowry et al. (19) using bovine serum albumin as standard.

Studies of the induction of the phagocytic respiratory burst by yeast cells. Generation of chemiluminescence by fungi added to PMN was quantified in a luminol or lucigenin amplified system by the methods of Trush et al. (20) and Allen (21). Briefly $10^{7}$ yeast cells were mixed with $10^{6} \mathrm{PMN}$ in a volume of $500 \mu \mathrm{l}$ of GBSS supplemented with 56 $\mu \mathrm{M}$ of luminol or $10^{-4} \mathrm{M}$ lucigenin at $37^{\circ} \mathrm{C}$, and the resulting light emission was measured on a LKB luminometer (model 1250, LKB Instruments, Luzerne, Switzerland) either by continuous recording at $37^{\circ} \mathrm{C}$ in a standing cuvette or for parallel studies of multiple fungi by intermittent measurements of cuvettes kept at $37^{\circ} \mathrm{C}$ in an agitating water bath. Induction of $\mathrm{H}_{2} \mathrm{O}_{2}$ secretion by yeasts was studied by the method of Root et al. (22) by quantifying the loss of fluorescence of scopoletin oxidized by $\mathrm{H}_{2} \mathrm{O}_{2}$ in the presence of horseradish peroxidase (HRP) (type IV, Sigma Chemical Co.) on a Perkin Elmer LS-5 fluorimeter (Perkin Elmer, Inc., Küsnacht, Switzerland).

Statistical analysis. Results of the killing assays were analyzed by 2 $\times k$ contingency tables, mean values were compared by $t$ test (23). The $\mathrm{ED}_{50}$ was computed by the method of Reed and Muench (24).

\section{Results}

Attack of PMN on hyphae and yeast. When PMN suspended in medium supplemented with $10 \%$ HS were sedimented in microwells that contained fungi, the phagocytes were randomly distributed on the bottom of the wells without contact with either hyphae or yeasts (Fig. 1). Within $15 \mathrm{~min}$ of incubation at $37^{\circ} \mathrm{C}$, PMN had migrated toward and covered hyphae and yeast cells (Fig. 1). All fungal species, opportunists and virulent dimorphic yeasts alike, attracted PMN and were similarly covered by phagocytes (not shown). Thus a failure of PMN to make contact with certain fungal species in our test system could not be responsible for their failure to sterilize microwells inoculated with particular fungi.

Characterization of the killing assay with hyphae from $C$. albicans. The influence of the time of incubation of PMN with fungi and of the number of CFU used to inoculate microwells on the fraction of microwells sterilized by the phagocytes is shown in Fig. 2. Killing, as determined by sterilization of microwells, only occurred under conditions that supported migration of PMN and attack of fungi, documenting the requirement for direct contact between PMN and fungi for sterilization. Thus, migration (as observed by phase-contrast microscopy) and killing did not occur if serum was omitted (Fig. 2), but complement was not essential. Heat-inactivated serum $\left(45 \mathrm{~min}, 56^{\circ} \mathrm{C}\right)$ was as effective as fresh serum in promoting the attack of PMN on fungi, and a similar percentage of wells inoculated with seven CFU of $C$. albicans was sterilized by PMN suspended in either fresh serum $(92 \%)$ or heat-inactivated serum $(89 \%, P>0.3)$. Similarly, antibody was not of importance because twofold adsorption of serum with $10^{8}$ live germ-tubes $/ \mathrm{ml}$, which reduced Ig binding by hyphae by $4 \log$ in an indirect whole cell enzymelinked immunosorbent assay (10), did not reduce either migration or the number of wells sterilized by PMN ( $96 \%$ of wells sterilized in the presence of adsorbed vs. $96 \%$ of wells in the presence of nonadsorbed serum). Finally, we found that migration of PMN and killing was supported by supplementing the medium with $4 \mathrm{mg} / \mathrm{ml}$ of human serum albumin (85\% of wells sterilized in the presence of human serum albumin vs. $94 \%$ in the presence of $10 \% \mathrm{HS}$ ). Thus, as in chemotaxis under agarose (25), the presence of protein in the medium appeared necessary to permit migration of PMN on the plastic surface in our assay. These observations are also in agreement with previous reports, that in a system in which fungi and PMN are tumbled in suspension, no humoral factors are required for PMN to attach to and damage fungal cells (12). Migration, and thus killing, were also inhibited by high concentrations $(5 \mathrm{mg} / \mathrm{ml})$ of mannan added to leukocytes immediately before incubation with the hyphae (Fig. 2), as expected from observations of Diamond et al. (26), on other in vitro systems, further documenting the necessity for a direct contact between PMN and fungi. Sterilization of microwells, but not attack on hyphae by PMN, was abolished by $0.1 \mathrm{mM}$ sodium azide added to leukocytes immediately before incubation with the fungus (Fig. 2). On the other hand, neither catalase $(500-10,000 \mathrm{U} / \mathrm{ml})$ nor superoxide dismutase (280-420 $\mathrm{U} / \mathrm{ml}$ ) affected killing, whether added only to the leukocytes or added to leukocytes and fungi $20 \mathrm{~min}$ before sedimentation of the PMN (data not shown). PMN were responsible for most of the antifungal activity because killing by the PMN fraction of leukocytes (>97\% PMN) and unfractionated leukocytes (63$72 \%$ PMN) was comparable ( $96 \%$ of wells sterilized vs. $100 \%$ with six CFU; and $75 \%$ vs. $81 \%$ with $18 \mathrm{CFU}, P>0.2$ ) but the same number of mononuclear cells was always significantly less active (Fig. 3).

Killing of the hyphae of other opportunistic fungi. PMN suspended in medium with $10 \%$ HS killed hyphae from $A$. fumigatus, $A$. niger, $A$. flavus, $R$. oryzae, $A$. corymbifera, Mucor spp., $P$. boydii, and $T$. capitatum at a rate comparable to $C$. albicans (Fig. 3). The fact that low concentrations of sodium azide also inhibited killing of these fungi (Table II) suggests an important contribution by the $\mathrm{H}_{2} \mathrm{O}_{2}$-myeloperoxidase-halide system in killing hyphae in our system. Again neither catalase (500-10,000 $\mathrm{U} / \mathrm{ml}$ as measured after exhaustive dialysis against phosphatebuffered saline) nor superoxide dismutase affected killing. This observation is at variance with previous observations on inhibition of PMN-induced damage to hyphae $(11,12)$ by these enzymes and might reflect a failure of these macromolecules to reach inhibitory concentrations at the site of contact between PMN and fungi in our system. Unfractionated blood leukocytes and purified PMN were equally active against all fungi (data not shown), but the mononuclear cell fraction always sterilized fewer 


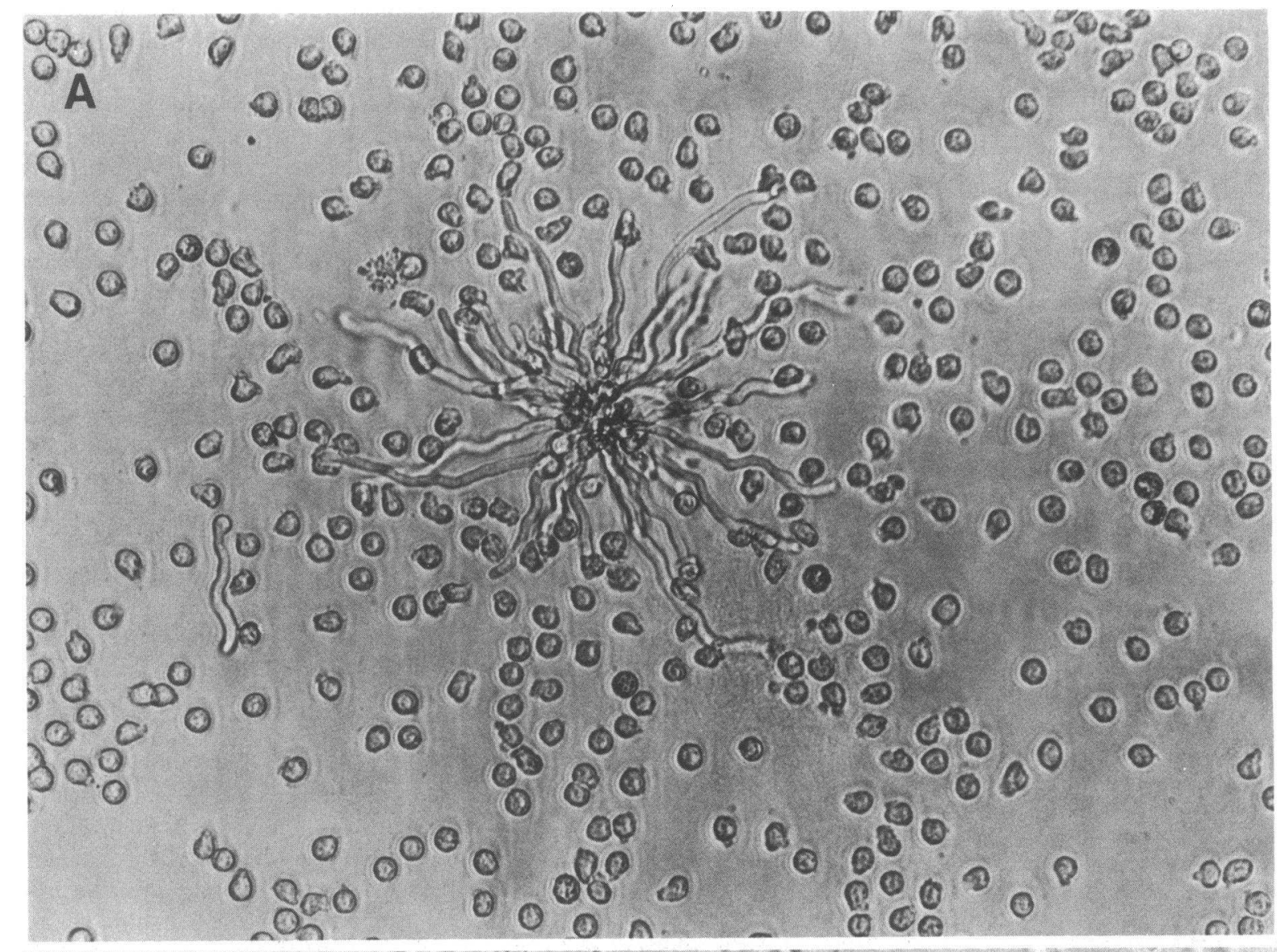

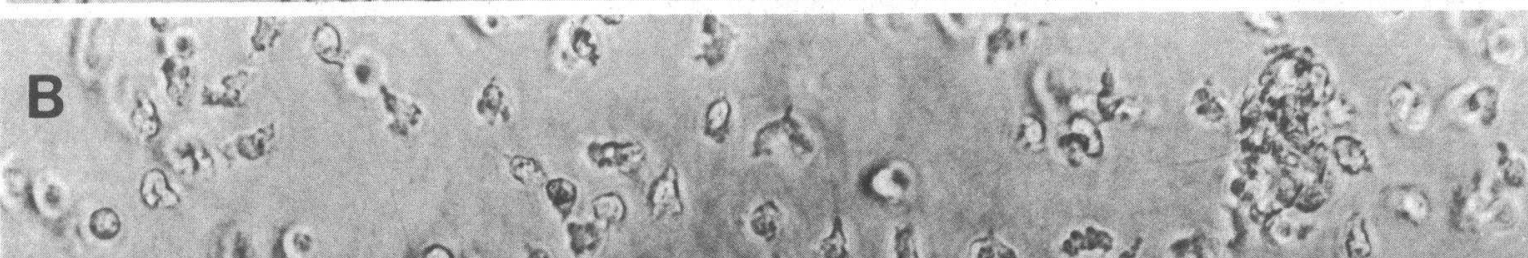

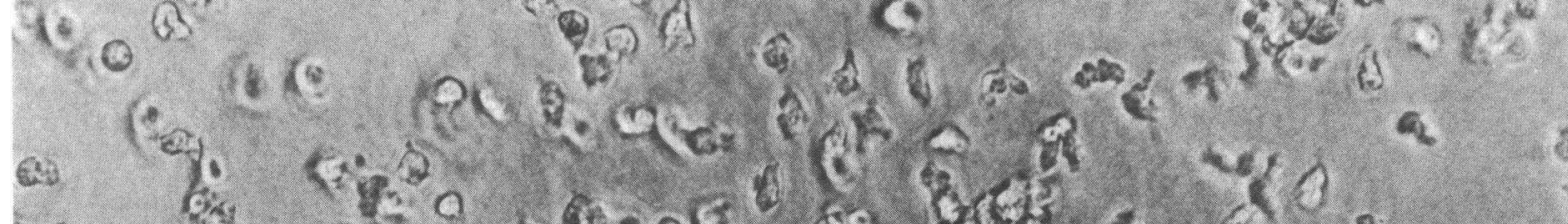

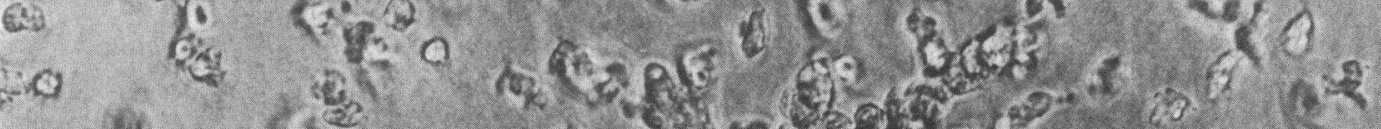

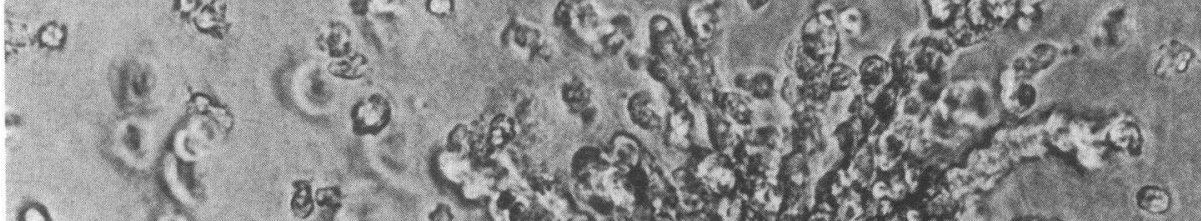

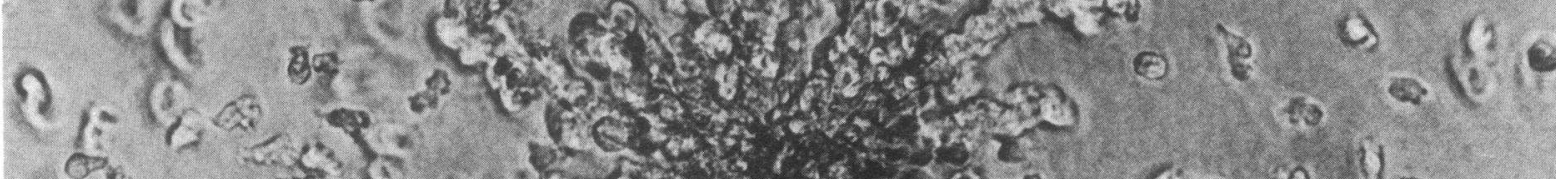

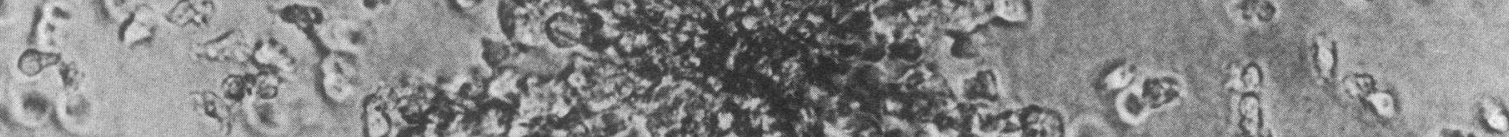

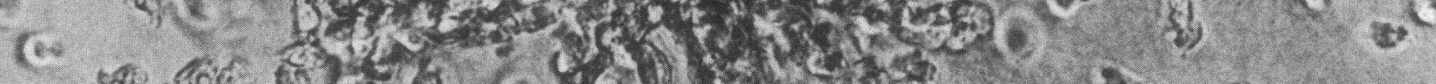
Fu

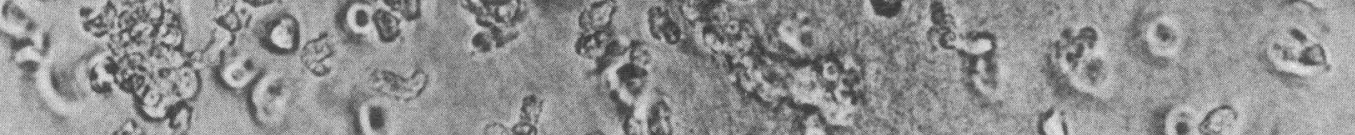

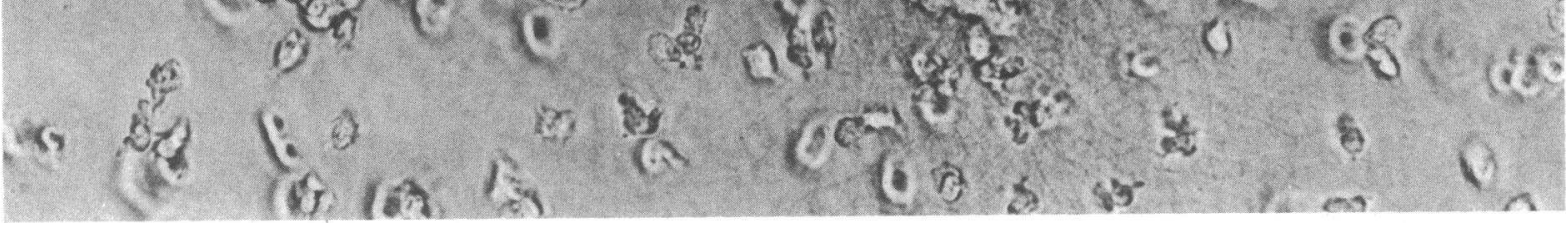




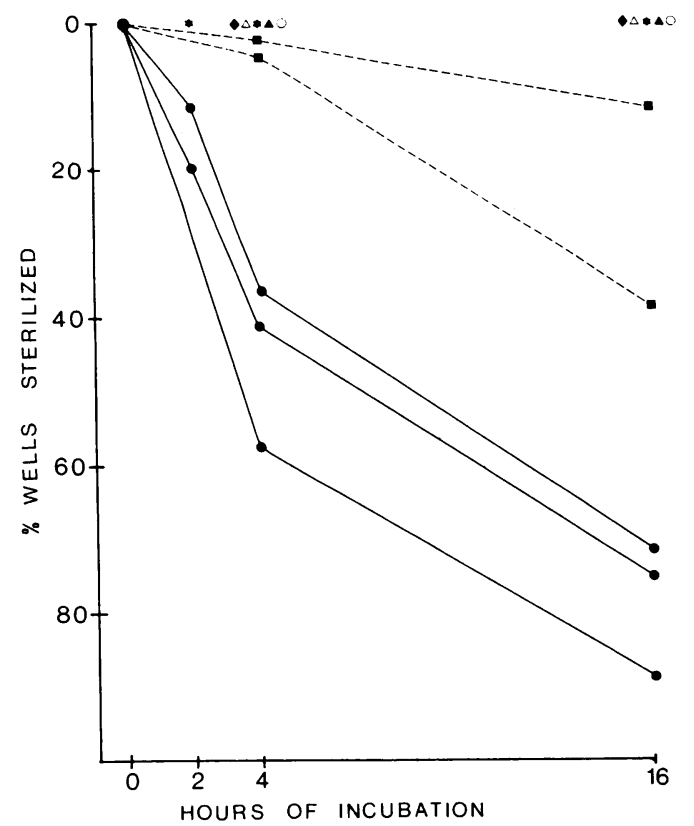

Figure 2. Sterilization by leukocytes of microwells containing hyphae of $C$. albicans. Percentage of wells $(n=48-96)$ sterilized by $1-2 \times 10^{5}$ leukocytes in MEM with $10 \%$ serum. Hours of incubation: time interval between addition of leukocytes and their lysis by distilled water. (๑) Sterilized by PMN; results of three independent experiments with 9 (bottom), 17 (middle), and 22 (top) CFU of Candida/well. (๓) Sterilization by the mononuclear cell fraction in parallel experiments with cells from the same donor. ( $\star$ ) Media controls. ( $\bullet$ PMN lysed by freezing and thawing. $(\Delta) \mathrm{PMN}$ with $0.1 \mathrm{mM}$ azide. (0) PMN in protein-free medium. (৯) PMN in medium supplemented with $10 \%$ serum and $5 \mathrm{mg} / \mathrm{ml}$ of mannan.

wells (Fig. 3, Table II), showing that the major killing capacity of blood leukocytes resided in the polymorphonuclear cell fraction. We suspected that blood monocytes were responsible for hyphal killing by the mononuclear cell fraction because their microbicidal systems are similar to PMN (27). Further fractionation of mononuclear cells by glass adherence supported this suspicion; glass-depleted cells ( $<10 \%$ monocytes) did not kill, but monocyte-enriched adherent cells ( $>65 \%$ monocytes) sterilized a substantial number of wells with hyphae (Table III). Monocytes were seemingly less active in sterilizing microwells than PMN, however, their purification required glass adherence which might alter cell function, and the test system that requires migration on a surface for attack on fungi might have handicapped monocytes against PMN.

Comparison of the susceptibility to killing by PMN of opportunistic yeasts, the yeast phase of dimorphic fungi and the saprophytic mycelial phase of dimorphic fungi. Yeast cells of the four virulent dimorphic fungi were resistant to sterilization by PMN (Fig. 4). When tested in parallel, wells inoculated with the two opportunistic yeasts, $C$. albicans and $T$. glabrata, were sterilized at a high rate, demonstrating an intact fungicidal function of the phagocytes in our assay and the capacity of the system to detect killing of yeast (Fig. 4). In contrast to the virulent tissue phase, the saprophytic phase of dimorphic fungi was susceptible to killing by PMN, in that wells with mycelia from $H$. capsulatum, $B$. dermatitidis, and $S$. schenkii were sterilized at a rate comparable to opportunistic monomorphic molds (Figs. 3 and 4). Wells with hyphae of $C$. albicans were sterilized at a rate comparable to that of wells with yeast cells, indicating that reverse dimorphism of Candida, in contrast to dimorphism of the primary pathogenic yeasts, was not decisive for the susceptibility to killing by PMN (Fig. 4).

Confirmation of the fundamental difference in the susceptibility of virulent dimorphic and opportunistic yeast to killing by PMN was first sought by different techniques in studies on the phagocyte-yeast interaction in suspension. Because $B$. dermatitidis tended to clump in suspension and because plating efficiency of $P$. brasiliensis $(\sim 50 \%)$ was unsatisfactory, these experiments were limited to a comparison of $H$. capsulatum and $S$. schenkii with $C$. albicans. When PMN and yeast were mixed at a ratio of 10:1 and incubated for $3 \mathrm{~h}$ and viability was determined over time by quantitative cultures, only the CFU of C. albicans were significantly reduced in spite of comparable phagocytosis of $>95 \%$ of all three fungi as determined by phasecontrast microscopy and giemsa-stained cytospin preparations. $S$. schenkii was completely resistant to killing and also the reduction in CFU of $H$. capsulatum of $7 \%$ was not significantly different from the count at the beginning of the experiment (Fig. 5). Because it had previously been suggested that alteration of stainability of $H$. capsulatum after phagocytosis by PMN reflected killing (28), we quantified alterations in the stainability of phagocytized fungi with basic dyes. As expected from the quantitative cultures, only C. albicans lost its stainability within $3 \mathrm{~h}$ after phagocytosis (Table IV). Next we investigated whether phagocytosis would induce ultrastructural changes of fungal cells that reflected damage and killing by PMN. Quantitation of ultrastructural alterations by electron microscopy confirmed the difference in the susceptibility of opportunistic and virulent dimorphic yeasts to killing by PMN (Fig. 6, Table IV).

Because yeast from Histoplasma, Blastomyces, Paracoccidioides, and to a lesser extent also from Sporothrix grow slower than opportunistic yeasts such as $C$. albicans, usually older cultures of the four virulent dimorphic yeasts were studied in parallel to opportunistic fungi. The possibility was therefore excluded that the difference between the susceptibility to killing by PMN might reflect metabolic differences between the growth phase of individual fungi studied, rather than interspecies differences (Fig. 7).

To assure that we were not misled by unique characteristics of the particular isolates that were selected for study, we expanded our observations to more strains and compared the susceptibility to PMN of five additional strains of Histoplasma and five additional strains of Sporothrix with that of 11 other isolates of opportunistic yeasts. Although PMN again killed all 11 strains of opportunistic yeasts, there was no significant reduction of CFU of the two virulent dimorphic fungi (Fig. 8).
Figure 1. (Opposite) Attack of fungal cells by human PMN. (A) To hyphae on the bottom of microwells, $1-2 \times 10^{5} \mathrm{PMN}$ in MEM with $10 \% \mathrm{HS}$ were added and sedimented at $100 \mathrm{~g}$ for $60 \mathrm{~s}$ resulting in a random distribution of phagocytes around hyphae. $(B)$ After $15 \mathrm{~min}$ of incubation at $37^{\circ} \mathrm{C}, \mathrm{PMN}$ have migrated toward and covered the fungal microcolony arising from a cluster of spores. To obtain this distribution pattern of fungi and phagocytes, spores were not disrupted or filtered in these experiments. (Aspergillus niger, original magnification $\times 200$ ). All fungal species shown in Figs. 2-4 were studied by phasecontrast microscopy and were attacked comparably by PMN. 
$\%$ Wells Sterilized

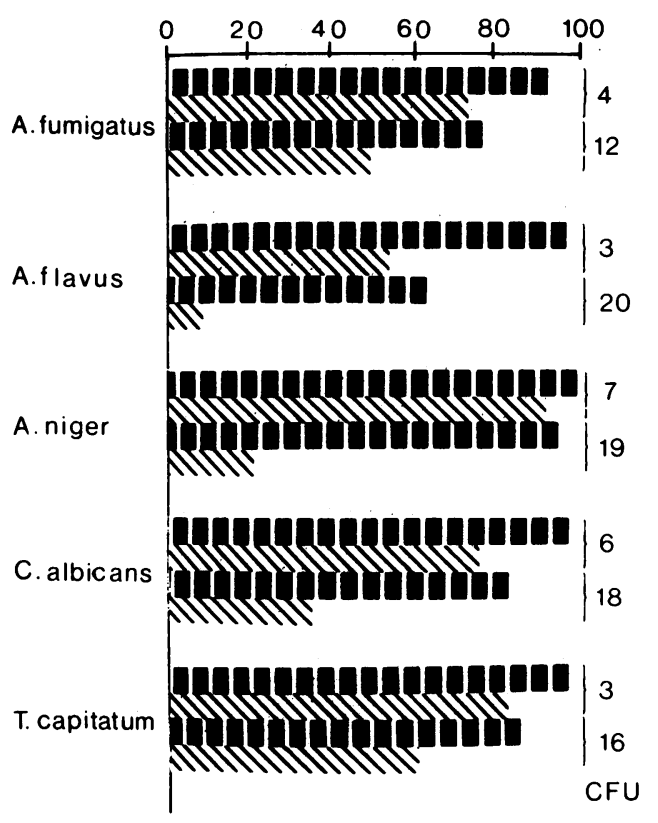

Figure 3. Sterilization of microwells with hyphae from a broad range of opportunistic fungi by human blood leukocytes. Results of one typical experiment are shown for each fungus. At least duplicate experiments were done for each fungus and gave similar results. Percentage of wells $(n=48-80)$ sterilized by leukocytes in $16 \mathrm{~h}$. Media controls

Furthermore, strain B-2 of Blastomyces and strain PB-2 of Paracoccidioides subcultured for $48 \mathrm{~h}$ from a log-phase broth culture were also found to be completely resistant to killing in the microwell assay which was slightly modified as "terminal dilution assay" to exclude the possibility that killing of a small fraction of yeast cells would escape detection in our standard

Table II. Antihyphal Activity of PMN, Inhibition by Azide, and Comparison with Mononuclear Blood Leukocytes*

\begin{tabular}{|c|c|c|c|}
\hline \multirow[b]{2}{*}{ Fungus (inoculum) } & \multicolumn{3}{|c|}{ Percentage of wells sterilized in $4 \mathrm{~h}$ by } \\
\hline & PMN & $\begin{array}{l}\text { PMN + } 0.1 \\
\text { mM azide }\end{array}$ & $\begin{array}{l}\text { Mononuclear } \\
\text { leukocytes }\end{array}$ \\
\hline & $\%$ & $\%$ & $\%$ \\
\hline C. albicans (9) & 56 & 0 & 6 \\
\hline A. flavus (7) & 65 & 27 & 2 \\
\hline A. niger (5) & 97 & 42 & 45 \\
\hline Mucor spp. (10) & 40 & 2 & 2 \\
\hline R. oryzae (6) & 78 & 0 & 15 \\
\hline P. boydii (8) & 59 & 0 & 0 \\
\hline$T$. capitatum (4) & 83 & 45 & 39 \\
\hline
\end{tabular}

* Wells were inoculated with yeast or spores (inoculum = mean value of CFU from five pour plates) and incubated until complete transformation to hyphae had occurred. The medium was replaced by $2 \times 10^{5}$ granulocytes (PMN, $>97 \%$ purity) or mononuclear blood leukocytes, cells sedimented with $100 \mathrm{~g}$ for $60 \mathrm{~s}$, and incubated for $4 \mathrm{~h}$ before lysis of cells and addition of fungal culture medium. Percentage of wells ( $n=48-96)$ with no fungal growth after $4 \mathrm{~d}$ of incubation. Control wells without leukocytes were $100 \%$ positive for fungal growth. Results from seven independent experiments.
$\%$ Wells Sterilized

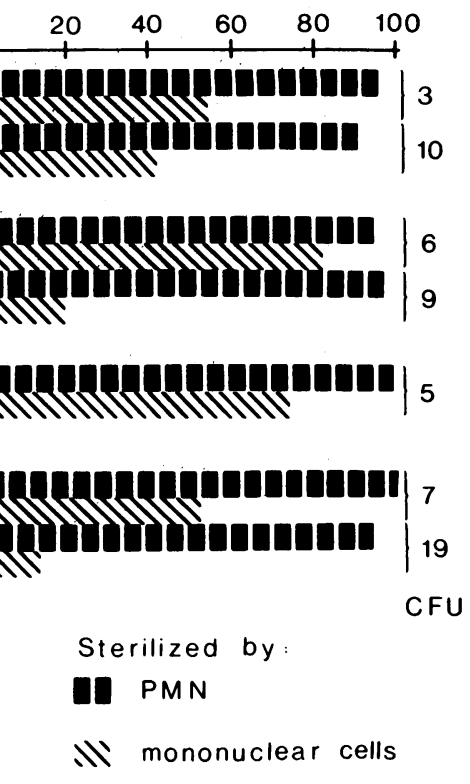

without PMN and with PMN lysed by freezing and thawing were done in each experiment and always produced hyphae in $100 \%$ of wells. Numbers on top of the bars indicate the number of CFU of yeast or spores used to induce hyphae.

assay (Fig. 9). Thus the difference between the susceptibility of opportunistic and primary pathogenic fungi was not limited to a few species or strains but was uniform for all isolates tested.

Induction of the phagocytic respiratory burst by yeast cells. To test the possibility that virulent dimorphic yeasts were not killed by PMN because they failed to trigger the production of

Table III. Comparison of the Antifungal Activity of Mononuclear Blood Leukocytes Enriched in or Depleted of Monocytes by Glass Adherence*

\begin{tabular}{lll}
\hline & $\begin{array}{l}\text { Percentage of wells sterilized } \\
\text { in } 16 \mathrm{~h} \text { by }\end{array}$ \\
\cline { 2 - 3 } Fungus (inoculum) & $\begin{array}{l}\text { Monocytes } \\
(>65 \%)\end{array}$ & $\begin{array}{l}\text { Lymphocytes } \\
(>90 \%)\end{array}$ \\
\hline & $\%$ & $\%$ \\
C. albicans (22) & 16 & 0 \\
A. niger (7) & 95 & 7 \\
R. oryzae (3) & 33 & 0 \\
T. capitatum (4) & 66 & 6 \\
\hline
\end{tabular}

* Wells were inoculated with yeast or spores (inoculum = mean value of CFU from five pour plates) and incubated until complete transformation to hyphae had occurred; medium was replaced by $2 \times 10^{5}$ mononuclear blood leukocytes enriched in or depleted of monocytes by glass adherence; leukocytes were sedimented with $100 \mathrm{~g}$ for $60 \mathrm{~s}$, and incubated for $16 \mathrm{~h}$ before lysis of cells and addition of fungal culture medium. Percentage of wells $(n=48-96)$ with no fungal growth after $4 \mathrm{~d}$ of incubation. Control wells without leukocytes were $100 \%$ positive for fungal growth. Results from four independent experiments. 


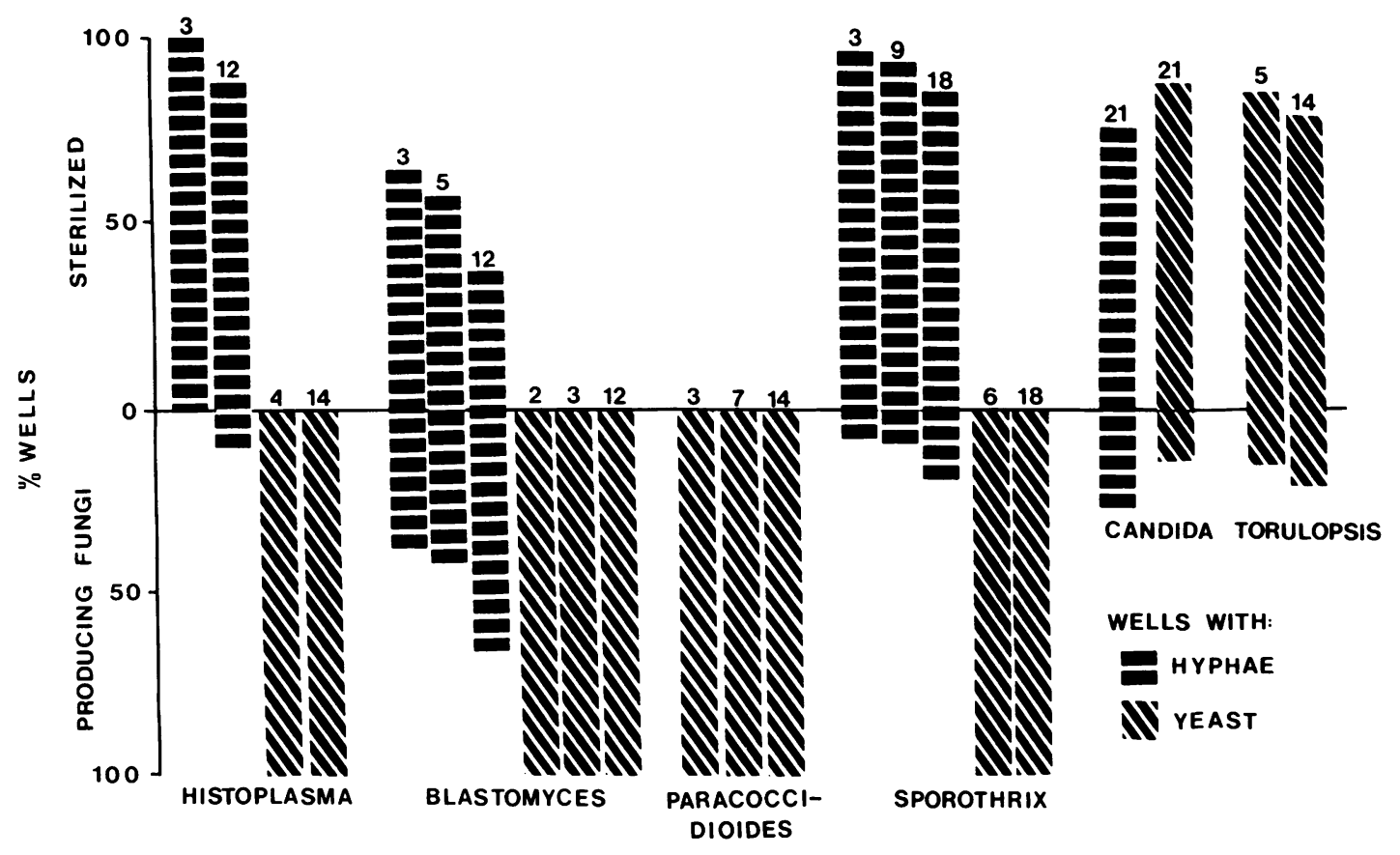

Figure 4. Sterilization by PMN of microwells containing hyphae or yeast cells from virulent dimorphic fungi and $C$. albicans or cells from the opportunistic yeast $T$. glabrata. PMN $\left(1.5 \times 10^{5} /\right.$ well $)$ were incubated for $16 \mathrm{~h}$ with fungal cells prior to lysis. Percentage of wells $(n$

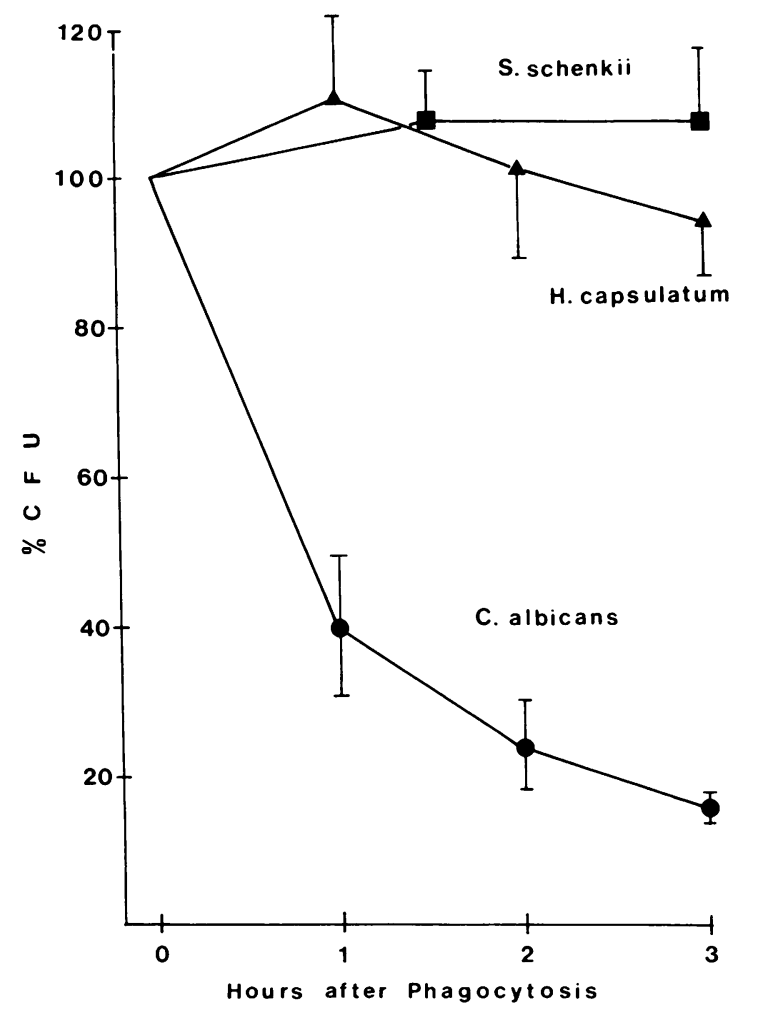

Figure 5. Effect of phagocytosis by PMN on viability of $H$. capsulatum, $S$. schenkii, and C. albicans. A suspension of $5 \times 10^{5}$ yeast cells and $5 \times 10^{6} \mathrm{PMN}$ was mixed and incubated on a rotary shaker. Within $1 \mathrm{~h}>95 \%$ of yeast cells were ingested by PMN as determined by Giemsa-stained cytospin preparations. At indicated times viability was determined by quantitative cultures on blood agar plates. Mean and standard deviation from two independent experiments with triplicate wells. The viability of $H$. capsulatum at $3 \mathrm{~h}$ is not significantly different from the initial value $(P>0.2$, two-tailed $t$ test).

= 48-96) sterilized by PMN or producing fungi. $100 \%$ of media controls produced fungal growth. The numbers on the top of the bars indicate the number of CFU of yeast added to individual wells. Results from a representative experiment out of three.

reactive oxygen intermediates by $\mathrm{PMN}$, we studied next the induction of chemiluminescence by yeast cells as a measure of the respiratory burst. Although only modest chemiluminescence was

Table IV. Effect of Phagocytosis by PMN on Ultrastructure and Stainability of Yeast Cells

\begin{tabular}{|c|c|c|c|}
\hline & Candida & Histoplasma & Sporothrix \\
\hline Cells evaluated $(n)$ & 59 & 556 & 143 \\
\hline \% lysed* & 39 & 0.5 & 6 \\
\hline \% partially damaged $\ddagger$ & 34 & 2.0 & 0.3 \\
\hline$\%$ lysed or damaged & 73 & 2.5 & 6.3 \\
\hline
\end{tabular}

Loss of stainability of yeast cells phagocytized by PMN for $3 \mathrm{~h}$

\begin{tabular}{llcc} 
Loss of stainability of yeast cells phagocytized by PMN for $3 \mathrm{~h}$ & \\
& Candida & Histoplasma & Sporothrix \\
\hline $\begin{array}{c}\% \text { cells with loss of } \\
\text { stainability§ }\end{array}$ & 57.5 & 0 & 0 \\
\hline
\end{tabular}

* (a) "Ghost" cells with loss of organelles and cytoplasmatic matrix or (b) discontinuous cell membrane and clumped chromatin. The percentage of fungal cells found to be lysed at the beginning of incubation has been subtracted from the given values ( $\mathrm{C}$. albicans, $0 \%$; Histoplasma, 6\%; and Sporothrix, 0.3\%).

$\ddagger(a)$ Thinning of cell wall (Candida only), large cytoplasmic vacuoles and/or $(b)$ increase in cell volume within an unruptured cell wall and cytoplasmic membrane, accompanied by altered mitochondrial structure.

$\S$ Cytospin preparations were stained by the May-Giemsa-Grünwald method and the percentage of phagocytized yeast cells that lost stainability during incubation with PMN was enumerated among 800 cells from eight slides and two independent experiments (for methods of interpretation see Lehrer [14]). 


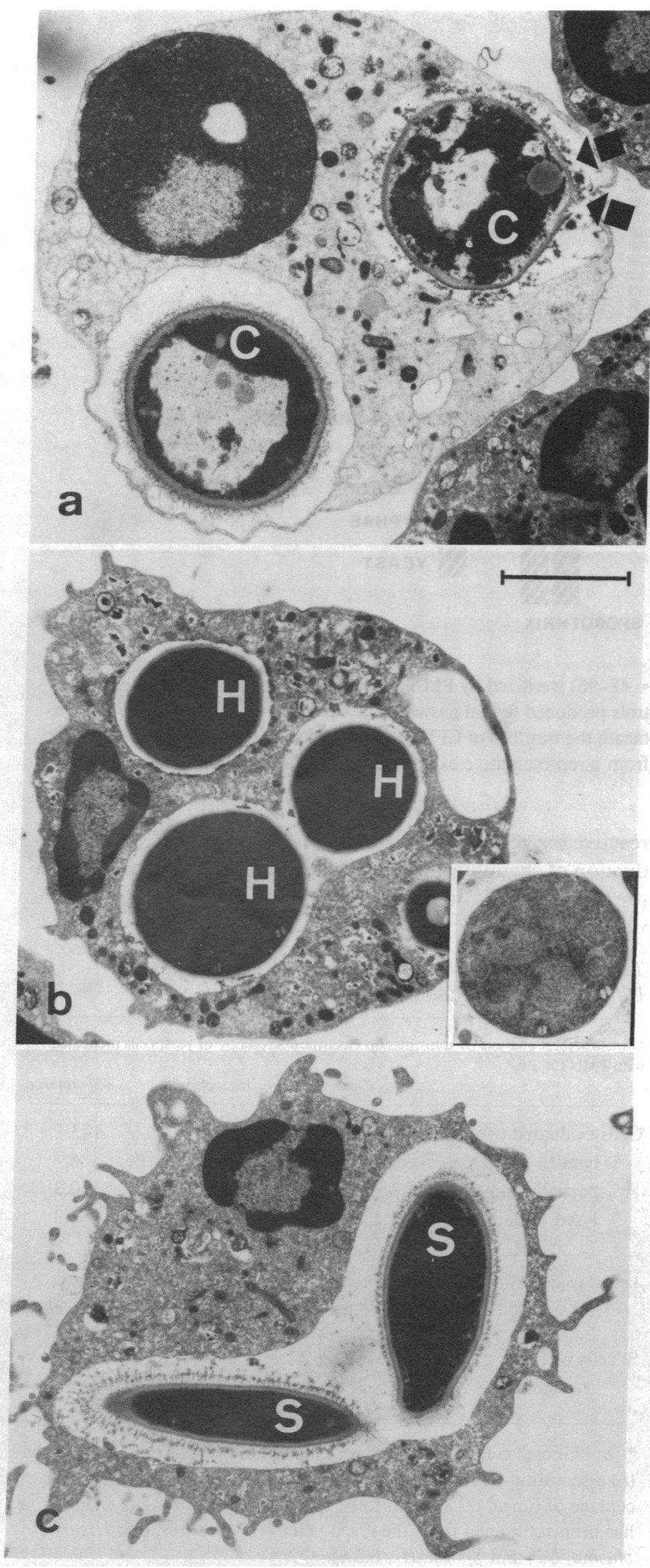

Figure 6. Ultrastructural appearance of phagocytized fungi $3 \mathrm{~h}$ after incubation with PMN. (a) Candida $(C)$ were in part effete with ruptured cell walls and cytoplasmic membranes (arrows on upper organism) and in part structurally altered with enlarged central vecuoles and condensed cytoplasm (lower yeast cell). (b) Histoplasma cells $(H)$ remained intact within phagosomes; inset shows the lowest yeast cell taken at longer photographic exposure to demonstrate intact mitochondria. (c) Sporothrix $(S)$ does not show signs of phagocytic attack. Bar (middle panel), $2 \mu \mathrm{m}$.

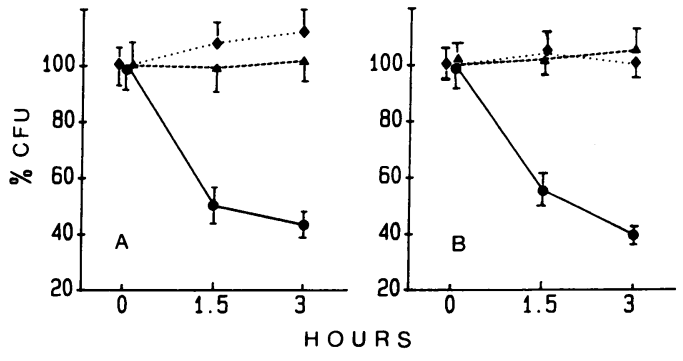

Figure 7. Lack of influence of the age of fungal cultures on the susceptibility of yeast to killing by PMN. Broth cultures of $C$. albicans, $S$. schenkii, and $H$. capsulatum were subcultured for $18 \mathrm{~h}(A)$ and $6 \mathrm{~d}(B)$ in BHI broth prior to phagocytosis by PMN. Each point represents the mean and standard deviation of the percentage of CFU from quadru-

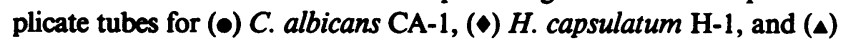
S. schenkii S-1.

produced by PMN mixed with nonopsonized yeast of $C$. albicans, Histoplasma, Sporothrix, or Paracoccidioides (Fig. 10 A), the same fungi induced a strong response in the presence of fresh human serum (Fig. $10 \mathrm{~B}$ ) or after opsonization in fresh HS (Fig. $10 \mathrm{C}$ ). Although Blastomyces seemingly triggered a notable burst in the absence of opsonins, controls without PMN showed that Blastomyces itself produced enough $\mathrm{H}_{2} \mathrm{O}_{2}$ to account for most of the recorded chemiluminescence (Fig. $10 \mathrm{~A}$ ). That it was $\mathrm{H}_{2} \mathrm{O}_{2}$ which was responsible for luminol-amplified chemiluminescence by Blastomyces was proved by its inhibition by catalase (not shown) and by directly measuring $\mathrm{H}_{2} \mathrm{O}_{2}$ production by the scopoletin-HRP method in which Blastomyces produced 6-7 nmol of $\mathrm{H}_{2} \mathrm{O}_{2} / 10^{7}$ cells/min compared with $<1 \mathrm{nmol} / 10^{7}$ cells $/ \mathrm{min}$ by each of the other four fungi. Induction of phagocytic chemiluminescence by Blastomyces could, however, be demonstrated by using lucigenin as probe. Lucigenin, which differs from luminol in its reactivity with oxygen intermediates (21), did not react with $\mathrm{H}_{2} \mathrm{O}_{2}$ produced by Blastomyces under our conditions of study and permitted the recording of an unequivocal phagocytic burst without fungal background activity (maximum recordings within $30 \mathrm{~min}$ : for opsonized Blastomyces with PMN, $46.4 \mathrm{mV}$; for Blastomyces without PMN with or without $20 \mu \mathrm{g} / \mathrm{ml}$ of HRP, $0.2 \mathrm{mV}$; and for PMN alone, $4.0 \mathrm{mV}$ ). Induction of the respiratory burst by $C$. albicans, Histoplasma, Sporothrix, and $P$. brasiliensis was further confirmed by lucigenin-amplified chemiluminescence and by demonstration of induction of $\mathrm{H}_{2} \mathrm{O}_{2}$ production by $\mathrm{HRP}$ mediated scopoletin oxidation (not shown). In summary, these experiments demonstrated that, in the presence of opsonins, all primary pathogenic yeasts induce a respiratory burst. It could be argued that the magnitude of the burst induced by the primary pathogens is less than that induced by Candida (Fig. 10), but the differences in the size of the various yeast cells (Candida is second in size only to Blastomyces) and the sedimentation velocity of the fungi in the cell mixture demand caution in the interpretation of these quantitative differences.

Susceptibility of fungi to oxidants. Inasmuch as several previous studies (11-14) indicated that the $\mathrm{H}_{2} \mathrm{O}_{2}$-myeloperoxidasehalide system plays an important role in the process of killing fungi, and because azide protected opportunists from killing in this study, we investigated the possibility that the innate resistance of virulent yeasts to reactive oxygen intermediates might be responsible for their resistance to killing by PMN. Indeed, the tissue phase of the four virulent dimorphic fungi was much less susceptible to killing by $\mathrm{H}_{2} \mathrm{O}_{2}$ than a broad range of opportunistic 


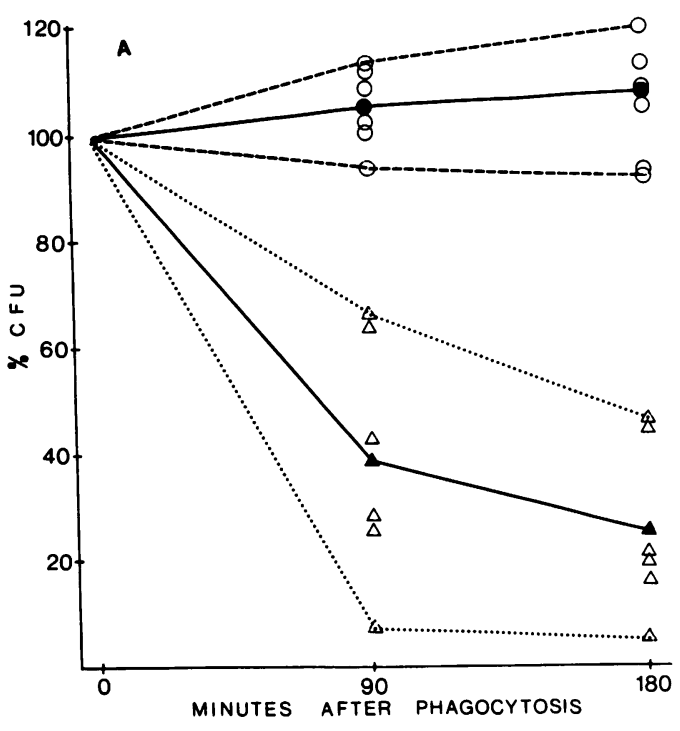

Figure 8. $(A)$ Effect of phagocytosis by PMN on viability of different isolates of $H$. capsulatum $(\bullet, 0)$ and $C$. albicans $(\Delta, \Delta)$. Mean $(\bullet, \Delta)$ and range $(0, \Delta)$ of the change in the percentage of CFU over time from six strains (H-1 through H-6 from Table I) from triplicate experiments studied in parallel with six strains of $C$. albicans (CA-1 through CA-6 from Table I). (B) Effect of phagocytosis by PMN on viability of

fungi or the saprophytic phase of dimorphic fungi (Table V). Again the difference between the susceptibility of various species appeared independent from the growth phase of the yeast culture studied as shown for C. albicans, Sporothrix, and Histoplasma (Fig. 11). However, a comparison of the susceptibility of different fungi to $\mathrm{ClO}^{-}$, which is presumed to be an important oxidative product of the myeloperoxidase system (29), did not discriminate between the two categories of fungi (Table VI). Similarly, we found no difference in the susceptibility of opportunistic and primary pathogenic fungi to $\mathrm{H}_{2} \mathrm{O}_{2}-\mathrm{Fe}^{++}$-iodide, a system in which $\mathrm{Fe}^{++}$replaces myeloperoxidase (30) and which results in efficient iodination of $C$. albicans and $A$. fumigatus (31). Finally, we looked at the catalase activity of a broad range of opportunistic and primary pathogenic yeasts to investigate the possibility that different levels of catalase activity of primary pathogens and opportunists might explain the difference in their susceptibility to $\mathrm{H}_{2} \mathrm{O}_{2}$ or PMN. However, the catalase activity of the various

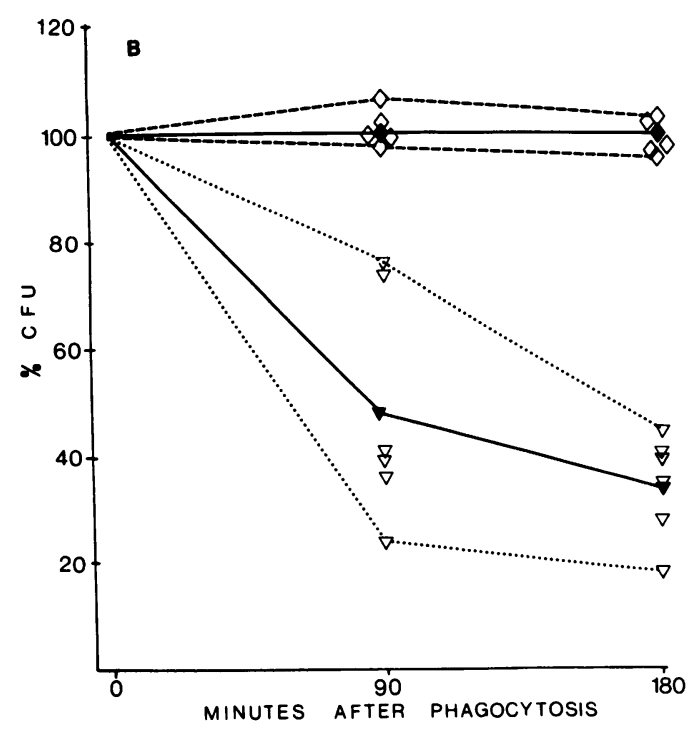

different isolates of $S$. schenkii $(\diamond, \diamond)$ and opportunistic yeasts $(\nabla, \nabla)$. Mean $(\diamond, \nabla)$ and range $(\diamond, \nabla)$ of the change in the percentage of CFU over time from five strains (S-2 through S-6 from Table I) from triplicate experiments studied in parallel with five strains of Candida spp. (C. krusei CK, C. tropicalis CT, C. parapsilosis CP, C. pseudotropicalis CPT, $C$. albicans CA-1 from Table I) and $T$. glabrata.

fungi was in the same order of magnitude and did not correlate with the susceptibility to $\mathrm{H}_{2} \mathrm{O}_{2}$ or PMN (Table VII).

\section{Discussion}

These studies were stimulated by the fundamental difference between the virulence of a few dimorphic fungi, which can cause serious disease in individuals with intact phagocytic defense systems, and most other fungi which cause life-threatening infections only in the immunocompromised. In vitro studies indicating that PMN contribute to natural resistance against opportunistic yeasts (12-14), A. fumigatus $(10,11)$, and Rhizopus (11), and our study showing that the high resistance to experimental aspergillosis is mediated by phagocytes in the absence of specific immunity (10), caused us to speculate that PMN are the common denominator of the high natural resistance to opportunistic fungi, and that this defense system is ineffective
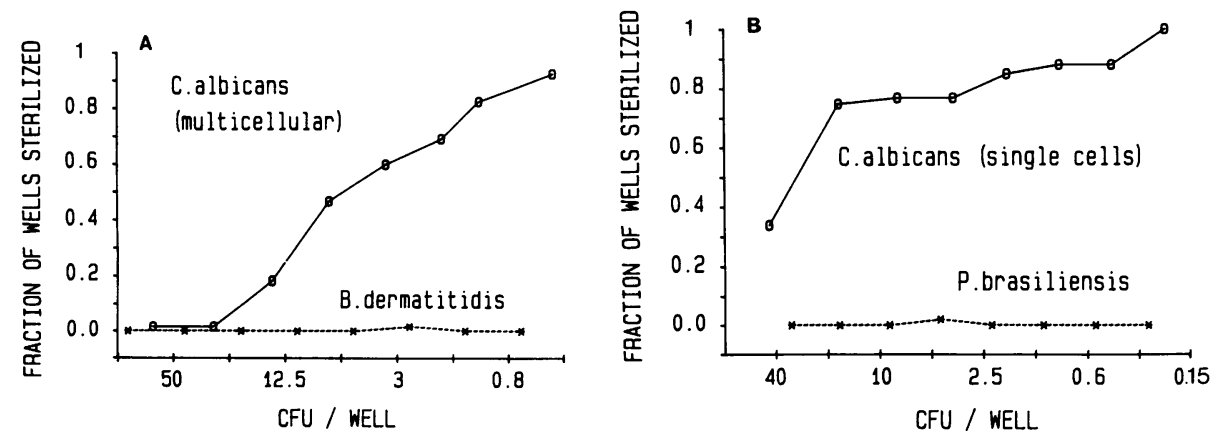

Figure 9. Failure of PMN to sterilize microwells inoculated with low numbers of yeast from $B$. dermatitidis (B-2) and $P$. brasiliensis (PB-2). Serial dilutions of yeast cells suspended in $50 \mu \mathrm{l}$ of MEM were dispensed to microwells prior to addition of $1.5 \times 10^{5} \mathrm{PMN}$ in $50 \mu \mathrm{l}$ of MEM with $20 \%$ serum, sedimentation of cells by centrifugation, and incubation for killing. The fraction of wells sterilized represents the number of control wells (MEM with 20\% serum) with fungal colonies after selective lysis of phagocytes and incubation for outgrowth of surviving fungi over the number of wells with fungal growth to which PMN were added. Each point represents the fraction of 120 wells. $(A)$ Aggregates of $C$. albicans (multicellular) were not disrupted (mean 1.8 cells per particle, including buds over one third the size of parent cells) to correct for the incomplete separation of yeast cells from $B$. dermatitidis by homogenization and filtration (mean 1.5 yeast cells per particle). $(B)$ There were less than 1.2 cells per particle for both fungi. CFU counts were from quadruplicate plates for numbers above two CFU, values for lower counts were obtained by prediction from a linear regression curve $(r>0.99$ for each curve). Each panel represents an independent experiment. 

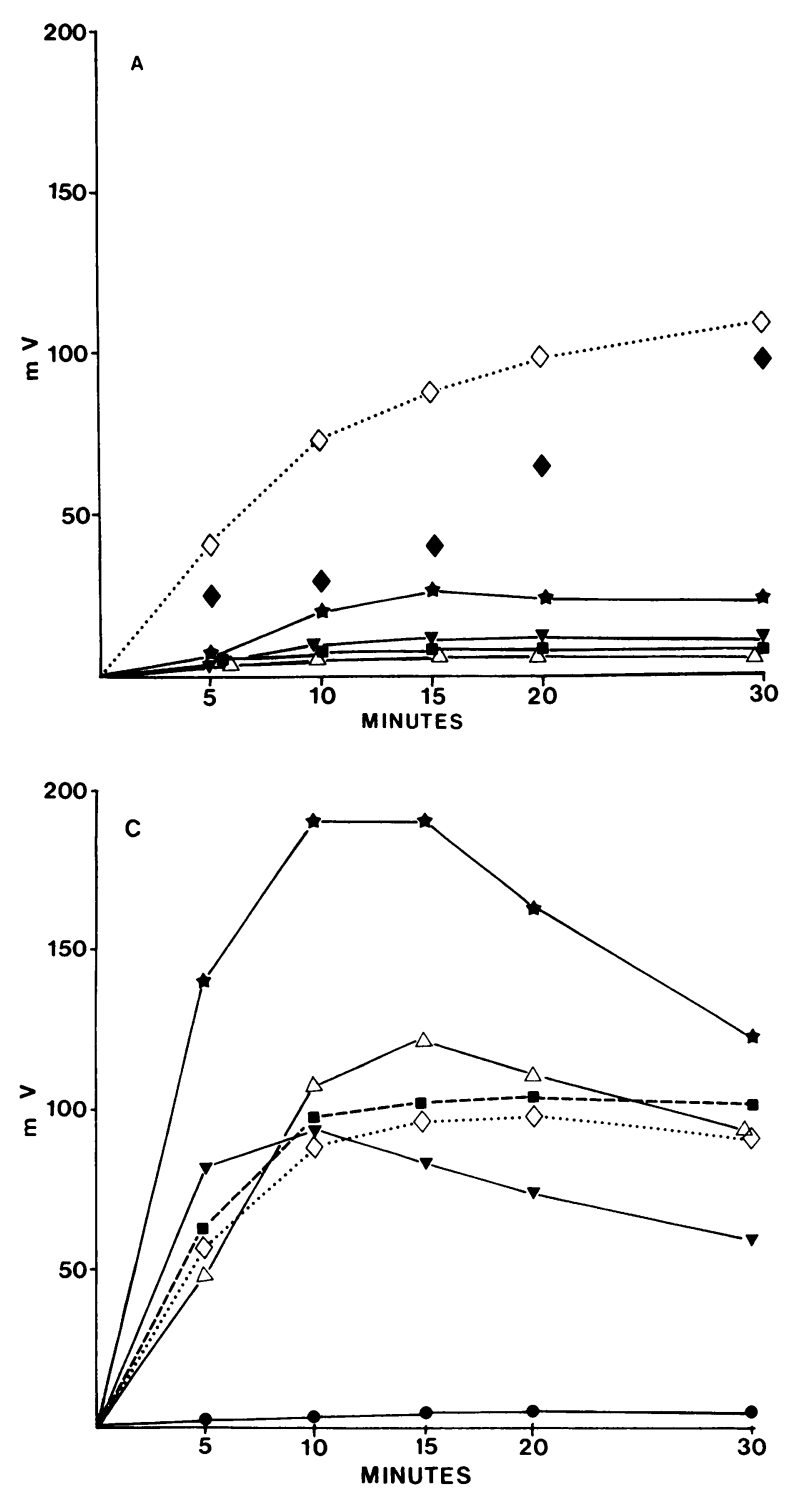

against the tissue phase of virulent dimorphic fungi. The experiments presented in this report show that in vitro susceptibility to killing by PMN does discriminate between primary pathogenic and opportunistic fungi. Hyphae and yeast from 14 opportunistic fungi were efficiently killed by PMN, but viability of the four virulent dimorphic yeasts was unaffected.

As expected from histopathologic studies of human disease and experimental infection $(4,7,10,32-36)$, which show that the inflammatory reaction to most fungi is mainly neutrophilic, PMN attacked or ingested opportunistic and virulent dimorphic fungi equally. Thus, the observed difference in killing of fungi by PMN cannot be explained by a failure of PMN to make contact with, or to ingest certain fungi. Furthermore, we found that in the presence of opsonins primary pathogenic yeasts triggered the respiratory burst of PMN comparable to $C$. albicans (Fig. 10). The primary pathogenic yeasts were much more resistant to $\mathrm{H}_{2} \mathrm{O}_{2}$ than a broad range of opportunistic hyphae or yeasts (Table $\mathrm{V}$ ), indicating that intrinsic resistance to oxidants might contribute to differences in the susceptibility to killing by PMN. This view is also supported by the observation that killing of opportunistic fungi was uniformly inhibited by low concentrations of azide, which indicates that the $\mathrm{H}_{2} \mathrm{O}_{2}$-myeloperoxidasehalide system contributes to killing of these fungi (29), as sug-

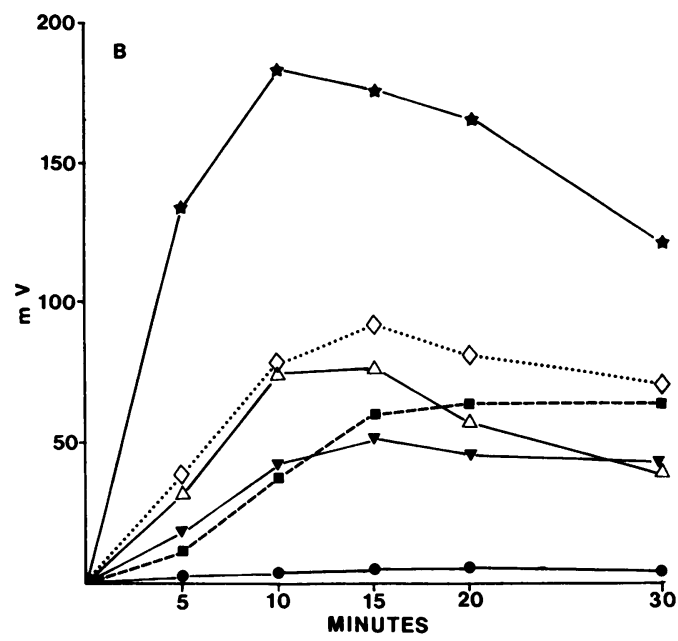

Figure 10. Induction of chemiluminescence by opportunistic and primary pathogenic yeasts in a luminol-amplified system. Response obtained from $10^{6} \mathrm{PMN}$ after stimulation with $10^{7}$ yeast cells, mean values from triplicate independent experiments. $(A)$ Response in millivolts obtained with nonopsonized yeast cells. $(B)$ Response obtained with yeast cells in the presence of $10 \%$ fresh HS. $(C)$ Response obtained by washed yeast cells opsonized for $30 \mathrm{~min}$ at $37^{\circ} \mathrm{C}$ in fresh HS. Induction of chemiluminescence by: $(\star) C$. albicans, $(\nabla) H$. capsu-

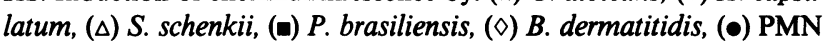
without yeast cells. With the exception of $B$. dermatitidis the yeast cells did not induce by themselves luminol-amplified chemiluminescence ( $<2 \mathrm{mV}$ ) whether HRP (to substitute for myeloperoxidase) was added to the system or not. However, $B$. dermatitidis produced enough $\mathrm{H}_{2} \mathrm{O}_{2}$ to display chemiluminescence in the presence of $\operatorname{HRP}(\diamond$, panel $A$ ).

gested by previous reports for a more limited number of fungi (11-14). However, the susceptibility to $\mathrm{ClO}^{-}$, probably an important oxidant of the myeloperoxidase system (24), or to a system composed of $\mathrm{H}_{2} \mathrm{O}_{2}-\mathrm{Fe}^{++}$-iodide, in which $\mathrm{Fe}^{++}$replaces myeloperoxidase (30), did not discriminate between opportunists and virulent fungi (Table VI). These results cast doubt on an assumption that the difference in the susceptibility of primary pathogenic and virulent fungi depends solely on the susceptibility to reactive oxygen intermediates and suggest that other factors such as susceptibility to nonoxidative killing systems might also play an important role.

Our findings extend the list of opportunistic fungi susceptible to killing by PMN. Like opportunistic yeasts (12-14 and Figs. 4-8), representative species of all important monomorphic molds were killed at a high rate by PMN in the absence of adoptive immune mechanisms. The importance of this defense system to natural resistance is supported by clinical observations that neutropenia (4-7) or PMN dysfunction (37) are the main risk factors for invasive opportunistic mycoses. Furthermore, with the exception of blood monocytes, which also can kill opportunistic fungi (38, 39 and Tables II and III), no alternative killing systems have been described. Opportunistic fungi are not killed by serum, even in the presence of antibodies, and T cell-mediated 
Table V. Susceptibility of Fungi to Hydrogen Peroxide*

\begin{tabular}{llcl}
\hline Fungal species & Phase & ED $_{\text {so }}$ & $(n)$ \\
\hline & & $m M$ & \\
Primary pathogens & & & \\
B. dermatitidis & Yeast & 196 & $(3)$ \\
& Mycelia & 4.3 & $(1)$ \\
H. capsulatum & Yeast & 225 & $(2)$ \\
& Mycelia & 1.6 & $(1)$ \\
S. schenkii & Yeast & 76 & $(3)$ \\
& Mycelia & 4.3 & $(3)$ \\
P. brasiliensis & Yeast & 100.5 & $(2)$ \\
Opportunists & & & \\
C. albicans & Yeast & 9.7 & $(3)$ \\
& Hyphae & 9.1 & $(3)$ \\
T. glabrata & Yeast & 10.8 & $(1)$ \\
C. parapsilosis & Yeast & 3.6 & $(2)$ \\
C. krusei & Yeast & 6.2 & $(1)$ \\
C. tropicalis & Yeast & 3.6 & $(1)$ \\
A. fumigatus & Mycelia & 7.9 & $(2)$ \\
A. flavus & Mycelia & 2.6 & $(1)$ \\
M. pusillus & Mycelia & 3.4 & $(1)$ \\
P. boydii & Mycelia & 1.2 & $(1)$ \\
& & & \\
\hline
\end{tabular}

* Serial 1:3 dilutions of $\mathrm{H}_{2} \mathrm{O}_{2}$ in phosphate-buffered saline, $\mathrm{pH}$ 7.4, were tested in 12 wells at each concentration. The $\mathrm{ED}_{50}$ corresponds to the concentration of $\mathrm{H}_{2} \mathrm{O}_{2}$ required to sterilize $50 \%$ of 12 wells (computed according to the methods of Reed and Muench [24]).

immunity is superfluous for resistance to experimental opportunistic mycoses, as shown for Aspergillus (10), Absidia (40), and Candida (41) in nude mice. The importance of blood monocytes is questionable in that the inflammatory response is mainly neutrophilic. Furthermore, immune defects that interfere with the mobilization of bone marrow-derived phagocytes prob-

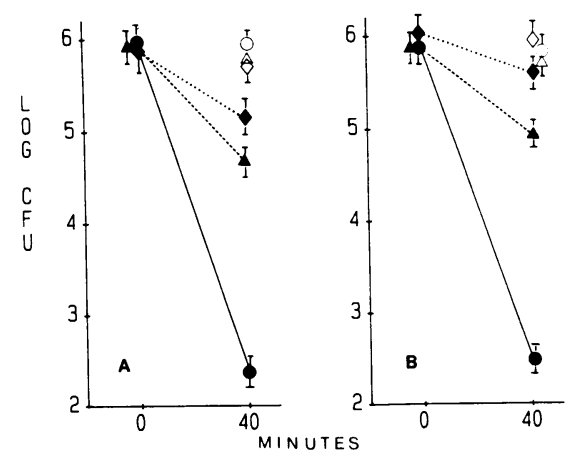

Figure 11. Lack of influence of the age of fungal cultures on the interspecies differences in the susceptibility to $\mathrm{H}_{2} \mathrm{O}_{2}$. To exclude that the recorded interspecies variations in the susceptibility to $\mathrm{H}_{2} \mathrm{O}_{2}$ were biased by unwanted differences in the growth phase of fungi, yeast cells from $H$. capslatum, $S$. schenkii, and $C$. albicans subcultured for $18 \mathrm{~h}(A)$ or $6 \mathrm{~d}(B)$ were incubated in $100 \mathrm{mM}$ of $\mathrm{H}_{2} \mathrm{O}_{2}$ in phosphatebuffered saline at $37^{\circ} \mathrm{C}$ to determine the rate of killing. Each point represents the mean and standard deviation from quadruplicate wells

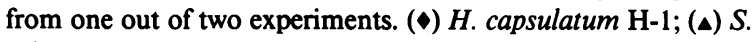
schenkii $\mathrm{S}-1 ;(\bullet) C$. albicans $\mathrm{CA}-1$. The empty symbols represent the appropriate buffer controls. In addition to the buffer controls, clumping of cells was excluded visually at the end of the experiments.
Table VI. Susceptibility of Yeasts to Hypochlorite and Hydrogen Peroxide in the Presence of $\mathrm{Fe}^{++}$and Iodide

\begin{tabular}{lll}
\hline Fungal species & $\mathrm{ED}_{50}$ of $\mathrm{ClO}^{-*}$ & $\begin{array}{l}\mathrm{ED}_{50} \text { of } \mathrm{H}_{2} \mathrm{O}_{2} \\
\left(+\mathrm{Fe}^{++}, \mathrm{J}^{-}\right) \ddagger\end{array}$ \\
\hline$\mu M$ & $m M$ \\
B. dermatitidis & 25.7 & 1.8 \\
H. capsulatum & 25.7 & 2.7 \\
S. schenkii & 10.5 & 24.5 \\
C. albicans & 12.0 & 2.1 \\
T. glabrata & 20.7 & 2.7 \\
C. tropicalis & 25.7 & 1.6 \\
C. krusei & 25.7 & 3.2 \\
C. parapsilosis & 14.5 & 1.6 \\
\hline
\end{tabular}

* Serial 1:3 dilutions of sodium hypochlorite in phosphate-buffered saline, $\mathrm{pH} 7.4$, were tested in six wells per concentration.

$\ddagger \mathrm{ED}_{\mathrm{s0}}$ of serial $1: 3$ dilutions of $\mathrm{H}_{2} \mathrm{O}_{2}$ in $0.1 \mathrm{mM}$ acetate buffer, $\mathrm{pH}$ 5.5 , supplemented with $10 \mu \mathrm{M} \mathrm{Fe}^{++}$and $100 \mu \mathrm{M} \mathrm{J}^{-}$(final concentrations). The $\mathrm{ED}_{\mathrm{so}}$ was computed according to the methods of Reed and Muench (24) from at least duplicate experiments for each fungus.

ably affect both cell lines, so that monocytes would not be expected to replace $P M N$ in this situation.

The finding that Blastomyces, Paracoccidioides, Sporothrix, and Histoplasma survive attack and phagocytosis by PMN extends previous reports that yeast from $B$. dermatitidis $(42,43)$ and spherules $(34,44)$ or endospores $(45)$ from $C$. immitis are resistant to killing by $\mathrm{PMN}$ in vitro. Our findings are, however, at variance with several other reports which suggested killing of the four virulent dimorphic yeasts by PMN in vitro. Thus it was proposed, based on alterations in the stainability of phagocytized yeast cells, that $H$. capsulatum is killed by PMN from guinea pigs in vitro (28) but alteration in stainability was not related to viability. In a preliminary study, it was found that human pe-

Table VII. Catalase Activity of Primary

Pathogenic and Opportunistic Yeasts

\begin{tabular}{ll}
\hline Fungus & Catalase activity* \\
\hline & $U / m g$ min $^{-1}$ \\
B. dermatitidis BD-1 & 4 \\
B. dermatitidis BD-2 & 6.5 \\
H. capsulatum H-1 & 11.5 \\
H. capsulatum H-3 & 8.5 \\
P. brasiliensis PB-1 & 8 \\
S. schenkii S-1 & 8.5 \\
S. schenkii S-3 & 6 \\
S. schenkii S-4 & 3.5 \\
C. albicans CA-1 & 11 \\
C. albicans CA-2 & 12 \\
C. albicans CA-3 & 11 \\
T. glabrata TG-1 & 10.5 \\
C. krusei CK-1 & 2.6
\end{tabular}

* Catalase activity was measured according to Lowry et al. (19) in cell homogenates from $10^{9}$ to $10^{10}$ yeasts broken with glass beads in phosphate buffer, $\mathrm{pH} 6.9$, supplemented with $0.25 \%$ deoxycholate. The given values adjusted for the protein concentration of the homogenates are from at least triplicate measurements. 
ripheral blood leukocytes reduced CFU of yeast from a strain of $H$. capsulatum (46). Based on the limited information available from this report it is not possible to locate possible differences with our experiments. However, our data consistently show by four different methods-sterilization of microwells (Fig. 4), reduction of CFU (Figs. 5, 7, and 8), preserved stainability with basic dyes (Table IV), and preserved ultrastructure (Fig. 6, Table IV)—with six different strains and with PMN preparations that killed $C$. albicans at a rate comparable to that reported from several laboratories $(13,14)$, that $H$. capsulatum survives phagocytosis by PMN. Similarly, we cannot account for the difference with a study reporting killing of $80 \%$ of an inoculum of $S$. schenkii by human peripheral blood leukocytes in suspension (47) but again point to the extensive confirmation of our finding that also $S$. schenkii survives phagocytosis by PMN by several techniques and with multiple strains (Figs. 4-7, and 8). Also, killing of yeast from $B$. dermatitidis by $\mathrm{PMN}$ has been reported. In one report in which a reduction of $\mathrm{CFU}$ counts of $B$. dermatitidis by PMN were recorded, the authors concluded that there is marked disparity between phagocytosis of the yeast from Blastomyces and killing, perhaps because of resistance of the fungus to granulocyte microbicidal mechanisms (48). It is of note that the modest reduction in CFU of $29 \%$ found in this study at a PMN to yeast ratio of 1:1 was lowered when the ratio of PMN to yeast was increased to $10: 1$, suggesting that clumping of yeast cells with PMN accounted at least in part for the reduction of CFU. Furthermore, in a recent report killing by blood leukocytes of a small fraction of yeast from $B$. dermatitidis was claimed on the basis of an altered permeability of yeast cells to methylene blue after exposure to PMN (49). However, in contrast to the original development of this method with $C$. albicans by Lehrer and Cline (50), no direct correlation of loss of dye exclusion and of viability was provided for $B$. dermatitidis (49). In agreement with reports from Brummer, Stevens, and Sugar $(42,43)$, we were unable based on the criterion of growth to find any reduction in viability of yeast from $B$. dermatitidis even at a very high PMN to yeast ratio and with only few fungal cells (Fig. 9). Finally, there is also a report on killing of yeast from $P$. brasiliensis by blood leukocytes in which a reduction of CFU counts at a leukocyte to yeast ratio of $1: 2$ to $1: 3$ was observed (51). This report is, however, difficult to appreciate because no attempt was made to control for the effect of clumping of yeast cells with PMN at this low ratio of phagocytes to yeast cells, which could easily lower CFU counts by $50-70 \%$. Brummer et al. (42) suggested that murine granulocytes when manipulated immunologically could kill yeast cells of Blastomyces. Although we found, in agreement with these authors, that PMN under standard conditions do not kill yeast from $B$. dermatitidis in vitro, this report cautions against drawing a premature conclusion that PMN play no role at all in resistance against the yeast phase of virulent dimorphic fungi in vivo. For example, PMN might suppress growth or even kill the fungi in collaboration with other defense factors. However, the uniformity of our findings on the susceptibility and resistance of opportunistic and primary pathogenic fungi to killing by PMN cannot be explained by chance alone. Our studies point to a systematic difference that correlates with the virulence of these pathogens and with clinical observations and animal studies.

Our finding that virulent dimorphic yeasts uniformly withstand killing by PMN provides an explanation for the requirement of cell-mediated immunity for the control of dimorphic, virulent fungi in experimental infections (52-55), and points to the reasons why these fungi can cause serious disease in individuals with intact phagocytic defenses. Furthermore, we substantiated the role of dimorphism in virulence by showing that only the yeast phase of Histoplasma, Sporothrix, and Blastomyces is resistant to killing by PMN. The saprophytic mycelial phase is as susceptible as opportunistic fungi. We do not know the reasons for the greater susceptibility of hyphae to PMN, but their large dimensions present more surface area for phagocytic attack.

In contrast to dimorphic primary pathogenic fungi, $C$. albicans, which grows in many artificial media as yeast, but mainly as hyphae in tissue ("reverse dimorphic") was susceptible to killing by PMN and the yeast and the hyphal phase of this fungus were killed alike. This finding is in accordance with the classification of Candida as an opportunist. Disseminated candidiasis is primarily a complication of neutropenia and granulocyte dysfunction (37). Cell-mediated immunity appears inessential for control of experimental systemic infection $(41,56)$ or disseminated infection in humans, as illustrated by the rarity of systemic disease relative to the frequency and severity of mucosal candidiasis in the uncomplicated acquired immunodeficiency syndrome (AIDS) (57). Similarly, individuals with congenital thymus aplasia and candidiasis are predisposed solely to the muco-cutaneous form of the disease and are highly resistant to hematogenous spread of Candida (58). Thus, it appears that $\mathrm{T}$ cell-dependent defense factors are decisive for protection from mucosal or cutaneous candidiasis, but not for disseminated disease. Defective T cell-mediated immunity of AIDS also does not appear to predispose to other disseminated opportunistic fungal infections with the important exception of Cryptococcus neoformans (57). Although this yeast is regarded by some as an opportunist, it causes serious infections of normal people (7). Its virulence is correlated with the antiphagocytic properties of its large capsule (59), which probably explains the importance of specific immunity for the control of this mycosis (60).

A classification of Histoplasma, Coccidioides, Blastomyces, Sporothrix, and Paracoccidioides as primary pathogens does not deny that these fungi apart from being capable of causing serious disease in apparently normal individuals also have opportunistic proclivities as do other primary pathogens such as Mycobacterium tuberculosis as recently shown for Histoplasma and possibly Coccidioides also in AIDS (61).

In conclusion, our findings suggest that the in vitro susceptibility of fungi to killing by PMN discriminates between primary pathogenicity and opportunism. They also underscore the importance of dimorphism to fungal virulence. In order to be a primary pathogen, a fungus must reproduce in the host in a morphologic form that is resistant to killing by PMN. This form cannot be mycelial because all hyphae are susceptible to killing by PMN. Only the yeast phase (or spherules) of the dimorphic, primary pathogenic fungi can resist attack by PMN and cause disease in otherwise healthy people.

\section{Acknowledgments}

We thank Eva End and Marlene Fischer for skillful technical assistance and Drs. G. P. Medoff, A. T. Londero, D. A. Stevens, P. Lavalle, and A. Polak for providing us many of the fungal strains.

This investigation was supported by grants 3.815 .83 and 3.875 .85 from the Swiss National Science Foundation, by Public Health Service International Research Fellowship 1 F05 TW 02935, and the EMDO Foundation. 


\section{References}

1. Austwick, P. K. 1966. The role of spores in allergies and mycosis of man and animals. In The Fungus Spores. Colston Res. Soc. Proc. Symp. 18:321-337.

2. Gregory, P. H. 1973. Microbiology of the Atmosphere. 2nd ed. Leonard Hill Ltd., London. 1-377.

3. Chitale, A., and Y. Bhende. 1965. The incidence of Candida albicans in throat and feces of healthy persons and patients on antibiotic therapy. J. Postgrad. Med. 11:30-34.

4. Rose, H. D., and B. Varkey. 1975. Deep mycotic infection in the hospitalized adult: a study of 123 patients. Medicine (Baltimore), 54: 499-507.

5. Baker, R. D. 1970. The phycomycoses. Ann. N.Y. Acad. Sci. 174: 592-7.

6. Young, R. C., J. E. Bennett, C. L. Vogel, P. P. Carbone, and V. T. Devita. 1970. Aspergillosis: the spectrum of the disease in 98 patients. Medicine (Baltimore). 49:147-173.

7. Emmons, C. W., C. H. Binford, and J. B. Utz. 1977. Medical Mycology. 3rd ed. Lea \& Febiger, Philadelphia. 1-592.

8. Wheat, L. J., T. G. Slama, H. E. Eitzen, R. B. Kohler, M. L. V. French, and J. L. Beisecker. 1981. A large urban outbreak of histoplasmosis: clinical features. Ann. Intern. Med. 94:31-37.

9. Ajello, L., E. W. Chick, and M. L. Furclow, editors. 1971. Histoplasmosis. Proceedings of the Second National Conference. Charles C Thomas, Springfield, IL. 1-516.

10. Schaffner, A., H. Douglas, and A. Braude. 1982. Selective protection against conidia by mononuclear and against mycelia by polymorphonuclear phagocytes in resistance to Aspergillus. J. Clin. Invest. 69:617-631.

11. Diamond, R. D., R. Krzesicki, B. Epstein, and W. Jao. 1978. Damage to hyphal forms of fungi by human leukocytes in vitro: a possible host defense mechanism in aspergillosis and mucormycosis. Am. J. Pathol. 91:313-328.

12. Diamond, R. D., R. A. Clark, and C. C. Haudenschild. 1980. Damage to Candida albicans hyphae and pseudohyphae by the myeloperoxidase system and oxidative products of neutrophil metabolism in vitro. J. Clin. Invest. 66:908-917.

13. Oh, M. K., G. E. Rodey, R. A. Good, R. A. Chilgren, and P. G. Quie. 1969. Defective candidacidal capacity of polymorphonuclear leukocytes in chronic granulomatous disease of childhood. J. Pediatr. 75: 300-303.

14. Lehrer, R. I. 1970. Measurement of candidacidal activity of specific leukocyte types in mixed cell populations. I. Normal, myeloperoxidase-deficient and chronic granulomatous disease neutrophils. Infect. Immun. 2:42-47.

15. Kerkering, T. M., A. Espinel-Ingraff, and S. Shadomy. 1979. Detection of Candida antigenemia by counterimmunoelectrophoresis in patients with invasive candidiasis. J. Infect. Dis. 140:659-664.

16. Boyüm, A. 1976. Isolation of lymphocytes, granulocytes and macrophages. Scand. J. Immunol. 5(Suppl. 5):9-15.

17. Löfgren, S., A. Tärnvik, M. Thore, and J. Carlsson. 1984. A wild and an attenuated strain of Francisella tularensis differ in susceptibility to hypochlorous acid: a possible explanation of their different handling by polymorphonuclear leukocytes. Infect. Immun. 43:730-734.

18. Aebi, H. 1974. Katalase. In Methoden der enzymatischen Analyse. H. U. Bergemeier, editor. 3rd ed. Vol. 1, Weinheim, Verlag Chemie. 711-724.

19. Lowry, O. H., N. J. Rosebrough, A. L. Farr, and R. J. Randall. 1951. Protein measurement with the Folin phenol reagent. J. Biol. Chem. 193:265-275.

20. Trush, M. A., M. E. Wilson, and K. VanDyke. 1978. The generation of chemiluminescence (CL) by phagocytic cells. Methods En zymol. 57:462-494.

21. Allen, R. C. 1981. Lucigenine chemiluminescence: a new approach to the study of polymorphonuclear leukocyte redox activity. In Bioluminescence and Chemiluminescence. M. A. DeLuca and W. D. McEbroy, editors. Academic Press, Inc., New York. 63-73.
22. Root, R. K., J. Metcalf, N. Oshino, and B. Chance. 1975. $\mathrm{H}_{2} \mathrm{O}_{2}$ release from human granulocytes during phagocytosis. I. Documentation, quantitation, and some regulating factors. J. Clin. Invest. 55:945-955.

23. Sachs, L. 1978. Angewandte Statistik. 6th edition. Springer Verlag, Berlin. 195-296.

24. Reed, L. J., and H. Muench. 1938. A simple method of estimating fifty percent endpoints. Am. J. Hyg. 27:493-497.

25. Nelson, R. D., P. G. Quie, and R. I. Simmons. 1975. Chemotaxis under agarose: a new and simple method for measuring chemotaxis and spontaneous migration of human polymorphonuclear leukocytes and monocytes. J. Immunol. 115:1650-1656.

26. Diamond, R. D., F. Oppenheim, Y. Nakagawa, R. Krzesicki, and C. C. Haudenschild. 1980. Properties of a product of Candida albicans hyphae and pseudohyphae that inhibits contact between the fungi and human neutrophils in vitro. J. Immunol. 125:2797-2804.

27. Weiss, S. J., A. F. LoBuglio, and M. B. Kessler. 1980. Oxidative mechanisms of monocyte mediated cytotoxicity. Proc. Natl. Acad. Sci. USA. 77:584-587.

28. Howard, D. H. 1973. Fate of Histoplasma capsulatum in guinea pig polymorphonuclear leukocytes. Infect. Immun. 8:412-419.

29. Klebanoff, S. J. 1967. Myeloperoxidase-halide-hydrogen peroxide antibacterial system. J. Bacteriol. 95:2131-38.

30. Klebanoff, S. J. 1982. The iron- $\mathrm{H}_{2} \mathrm{O}_{2}$-iodide cytotoxic system. $J$. Exp. Med. 156:1262-1267.

31. Levitz, S. M., and R. D. Diamond. 1984. Killing of Aspergillus fumigatus spores and Candida albicans yeast phase by the iron-hydrogen peroxide-iodide cytotoxic system: comparison with the myeloperoxidasehydrogenperoxide-halide system. Infect. Immun. 43:1100-1102.

32. Bauer, H., and W. H. Sheldon. 1957. Leukopenia with granulocytopenia in experimental mucormycosis (Rhizopus oryzae infection). J. Exp. Med. 106:501-508.

33. Corbel, M. J., and S. M. Eades. 1976. The relative susceptibility of New Zealand Black and CBA mice to infection with opportunistic fungal pathogens. Sabouraudia. 14:17-32.

34. Baker, O., and A. Braude. 1956. A study of stimuli leading to the production of spherules in coccidioidomycosis. J. Lab. Clin. Med. 47:169-181.

35. Harvey, R. P., E. S. Schmid, C. C. Carrington, and D. A. Stevens. 1978. Mouse model of pulmonary blastomycosis: utility, simplicity and quantitative parameters. Am. Rev. Respir. Dis. 117:695-703.

36. Lurie, H. 1963. Histopathology of sporotrichosis. Arch. Pathol. 75:421-437.

37. Cohen, M. S., R. E. Isturiz, H. L. Malech, R. K. Root, C. M. Wilfert, L. Gutman, and R. H. Buckley. 1981. Fungal infection in chronic granulomatous disease. Am. J. Med. 71:59-66.

38. Diamond, R. D., C. C. Haudenschild, and N. F. Erickson III. 1982. Monocyte-mediated damage to Rhizopus oryzae hyphae in vitro. Infect. Immun. 38:292-297.

39. Lehrer, R. I. 1975. The fungicidal activity of human monocytes. I. Evidence for myeloperoxidase linked and myeloperoxidase independent candidacidal mechanisms. J. Clin. Invest. 55:338-346.

40. Corbel, M. J., and S. M. Eades. 1977. Experimental mucormycosis in congenitally athymic (nude) mice. Mycopathologia. 62:117-120.

41. Cutler, J. E. 1975. Acute systemic candidiasis in normal and congenitally thymus deficient (nude) mice. J. Reticuloendothel. Soc. 19: 121-124.

42. Brummer, E., A. M. Sugar, and D. A. Stevens. 1984. Immunological activation of polymorphonuclear neutrophils for fungal killing: studies with murine cells and Blastomyces dermatitidis in vitro. J. Leukocyte Biol. 36:505-520.

43. Brummer, E., and D. A. Stevens. 1984. Opposite effects of human monocytes and, macrophages and polymorphonuclear neutrophils on replication of Blastomyces dermatitidis in vitro. Infect. Immun. 36:297306.

44. Galgiani, J. N., R. Hayden, and C. M. Payne. 1982. Leukocyte effects on the dimorphism of Coccidioides immitis. J. Infect. Dis. 146: $56-63$. 
45. Beaman, L., and C. A. Holmberg. 1980. Interaction of nonhuman primate peripheral blood leukocytes and Coccidioides immitis in vitro. Infect. Immun. 29:1200-1208.

46. Holland, P. 1971. Circulating human phagocytes and histoplasma capsulatum. In Histoplasmosis. Proceedings of the Second National Conference. L. Ajello, E. W. Chick, and M. L. Furclow, editors. Charles C Thomas, Springfield, IL. 380-383.

47. Cunningham, K. M., G. S. Bulmer, and E. R. Rhodes. 1979. Phagocytosis and intracellular fate of Sporothrix schenkii. J. Infect. Dis. 140:815-817.

48. Sixbey, J. W., B. Y. Fields, C. N. Sun, R. A. Clark, and C. M. Nolan. 1979. Interaction between human granulocytes and Blastomyces dermatitidis. Infect. Immun. 23:41-44.

49. Drutz, D. J., and C. L. Frey. 1985. Intracellular and extracellular defenses of human phagocytes against Blastomyces dermatitidis conidia and yeasts. J. Lab. Clin. Med. 105:737-750.

50. Lehrer, R. I., and M. J. Cline. 1969. Interaction of C. albicans with human leukocytes and serum. J. Bacteriol. 98:996-1004.

51. Restropo, A. M., and H. A. Velez. 1975. Effectos de la fagocitosis in vitro sobre el Paracoccidioides brasiliensis. Sabouraudia. 13:10-21.

52. Beaman, L., D. Papaganis, and E. Benjamini. 1977. Significance of $\mathrm{T}$ cells in resistance to experimental murine coccidioidomycosis. Infect. Immun. 17:580-585.

53. Cozad, C. C., and C. T. Chang. 1980. Cell-mediated immunoprotection in blastomycosis. Infect. Immun. 28:398-403.

54. Shiraishi, A., K. Nakagaki, and P. Arai. 1979. Experimental spo- rotrichosis in congenitally athymic (nude) mice. J. Rethiculoendothel. Soc. $26: 333-336$.

55. Howard, D. H., and V. Otto. 1977. Experiments of lymphocytemediated cellular immunity in murine histoplasmosis. Infect. Immun $16: 226-231$.

56. Hurtrel, B., P. H. Lagrange, and J. C. Michel. 1981. Absence of correlation between delayed-type hypersensitivity and protection in experimental systemic candidiasis in immunized mice. Infect. Immun. 31: 95-101.

57. Centers for Disease Control Task Force on Kaposi's Sarcoma and Opportunistic Infections. 1982. Epidemiologic aspects of the current outbreak of Kaposi's sarcoma and opportunistic infections. N. Engl. J. Med. 306:248-252.

58. Edwards, J. E., Jr. 1978. Severe candida infections: clinical perspectives, immune defense mechanisms, and current concept of therapy. Ann. Intern. Med. 89:91-106.

59. Kozel, T. R., and E. C. Gotschlich. 1982. The capsule of Cryptococcus neoformans passively inhibits phagocytosis of the yeast by macrophages. J. Immunol. 129:1675-1680.

60. Cauley, L. K., and J. W. Murphy. 1979. Response of congenitally athymic (nude) and phenotypically normal mice to Cryptococcus neoformans infection. Infect. Immun. 23:644-651.

61. Armstrong, D., J. W. M. Gold, J. Dryanski, E. Whimbey, B. Polsky, C. Hawkins, A. E. Brown, E. Bernard, and T. E. Kiehn. 1985. Treatment of infections in patients with the acquired immunodeficiency syndrome. Ann. Intern. Med. 103:738-743. 